\title{
Representing Cross-border Trade of Electricity in Long-term Energy-System Optimization Models with a Limited Geographical Scope
}

\author{
Tim Mertens ${ }^{\mathrm{a}, \mathrm{b}, \mathrm{c}}$, Kris Poncelet ${ }^{\mathrm{a}, \mathrm{c}}$, Jan Duerinck $^{\mathrm{b}, \mathrm{c}}$, and Erik Delarue ${ }^{\mathrm{a}, \mathrm{c},{ }^{*}}$ \\ ${ }^{a}$ University of Leuven, Department of Mechanical Engineering, TME Branch, Celestijnenlaan 300, 3001 Heverlee \\ (Leuven), Belgium

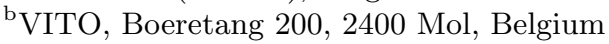 \\ ${ }^{\mathrm{c}}$ EnergyVille, Thor Park, 3600 Genk, Belgium
}

\begin{abstract}
Long-term energy system optimization models can be designed to model systems with a broad geographical scope that comprises multiple countries. However, due to computational limitations, often the geographical scope is restricted to a single country. This raises the problem of correctly accounting for cross-border trade of electricity in models with a limited geographical scope. Therefore, this paper assesses the impact of not correctly representing cross-border trade flows in geographically restricted long-term planning models. To this end, we use a planning model for the interconnected Central-Western European power system to compare technology choices and welfare estimates for Belgium when (i) cross-border trade of electricity is ignored and (ii) cross-border trade flows are an endogenous part of the planning model. Furthermore, this paper presents two sets of methodologies to account for transmission flows in planning models. A first methodology is to extend the model's geographical scope and fix the capacity variables in the neighboring countries in line with pre-designed scenarios for those countries. A second methodology further reduces the computational cost by using specially tailored import and export curves to represent each country's trade opportunities. The results indicate that for highly interconnected systems, neglecting cross-border trade or having a highly stylized representation of cross-border flows can lead to inaccurate welfare estimates and technology biases. In addition, a key insight presented in this paper is that congestion rents can constitute a major share of the welfare gains attained be trading electricity. Finally, endogenizing the dispatch decisions in neighboring countries is the most accurate method to deal with cross-border trade, while by correctly designing cross-border trade curves, computational time can be reduced, but planning model outcomes become less accurate.
\end{abstract}

Keywords - Long-term power system planning; energy-system optimization models; Crossborder trade; Transmission networks; Geographical scope.

${ }^{*}$ Corresponding author at: University of Leuven, Department of Mechanical Engineering, TME Branch, Celestijnenlaan 300, 3001 Heverlee (Leuven), Belgium. Tel: +32 163225 21. E-mail address: erik.delarue@kuleuven.be 


\section{Nomenclature}

\section{Abbreviations}

CAPEX Capital expenditures

CBT Cross-border trade

CCGT Combined cycle gas turbine

CR Congestion rent

CWE Central-Western Europe

NTC Net transfer capacity

OCGT Open cycle gas turbine

OPEX Operational expenditures

PV Photovoltaic

RES Renewable energy sources

TSO Transmission system operator

\section{Sets and indices}

$\bar{C} \quad$ Set of all neighboring countries, $\bar{C} \subset C$.

$\tilde{C} \quad$ Set containing the focus country, $\tilde{C} \subset C$, the focus country is indexed by $\tilde{c}$.

$C \quad$ Set of all countries, indexed by $c, c^{\prime}$.

$G \quad$ Set of all technologies, indexed by $g$.

$G_{D} \quad$ Subset of all dispatchable technologies, $G_{D} \subset$ $G$.

$G_{R} \quad$ Subset of all renewable technologies, $G_{R} \subset G$.

$S \quad$ Set of import/export stage, indexed by $s$.

$T \quad$ Set of time steps, indexed by $t$.

\section{Parameters}

$\Delta T \quad$ Time resolution, $h$.

$\Phi \quad$ Dummy transmission cost, $€ / M W h$.

$C A P_{c, g}$ Capacity projection for technology $g$ in neighboring country $c$.

$C F_{c, g, t}$ Normalized generation profile for technology $g \in G_{R}$ in country $c$.

$D_{c, t} \quad$ Electricity demand in country $c$ at time step $t, M W h / h$.

$F C_{g} \quad$ Fixed unit cost of technology $g, € / M W$.
$K_{c}^{e x p}$ Export transmission capacity of the interconnection with country $c, M W$.

$K_{c}^{i m p}$ Import transmission capacity of the interconnection with country $c, M W$.

$K_{c, c^{\prime}} \quad$ Transmission capacity for flows from country $c$ to country $c^{\prime}, M W$.

$P_{c, s, t}^{e x p} \quad$ Export revenue of export stage $s$ from country $c$ at time step $t, € / M W h$.

$P_{c, s, t}^{i m p} \quad$ Import cost of import stage $s$ from country $c$ at time step $t, € / M W h$.

$Q_{c, s, t}^{e x p} \quad$ Export capacity of import stage $s$ from country $c$ at time step $t, M W$.

$Q_{c, s, t}^{i m p}$ Import capacity of import stage $s$ from country $c$ at time step $t, M W$.

$V C_{g} \quad$ Variable generation cost of technology $g$, $€ / M W h$.

\section{Variables}

$c_{c a p}$ Installed capacity of technology $g$ in country $c, M W$.

$\exp _{c, s, t}$ Exported electricity from neighboring country $c$ and import stage $s$ in time step $t$, $M W h / h$.

$g e n_{c, g, t}$ Electricity generation of technology $g$ in time step $t$ and country $c, M W h / h$.

$i m p_{c, s, t}$ Imported electricity from neighboring country $c$ and import stage $s$ in time step $t$, $M W h / h$.

trans $_{c, c^{\prime}, t}$ Transmission flow from country $c$ to country $c^{\prime}$ in time step $t, M W h / h$.

\section{Other symbols}

$\lambda_{c} \quad$ Electricity price in country $c$.

$C A P E X_{c}$ Capital expenditures in country $c$.

$C R \quad$ Congestion rent.

$C V_{c} \quad$ Consumer value in country $c$.

$f \quad$ Transmission flow.

$O P E X_{c}$ Operational expenditures in country $c$.

$S W_{c} \quad$ Social welfare in country $c$. 


\section{Introduction}

Long-term energy-system and power-system optimization models, such as TIMES [1], and ReEDS [2] are widely used to analyze transition pathways for the energy system and power system. In the recent decades, such models have in particular been used to assess the techno-economic feasibility of different decarbonization pathways and the role that specific technologies or policies play in these decarbonization pathways. For example, the Belgian TIMES model is used in [3] to investigate scenarios that facilitate a $100 \%$ renewable energy system for Belgium by 2050. Similar exercises are performed in [4] and [5] for respectively the Irish and Danish energy systems. Analyses using energy-system optimization models focusing on specific technologies can be found in [6] (Hydrogen) and [7] (Carbon capture \& storage).

In this context, a particular challenge for such long-term planning models is to accurately represent the technical and economic challenges related to integrating high shares of variable and limitedly predictable renewable energy sources (RES) such as solar photovoltaics and wind turbines. Indeed, to maintain computational tractability, these long-term planning models typically use a limited temporal and spatial resolution, and generally do not represent the operational constraints that restrict the flexibility that can be provided by conventional power plants. In this regard, efforts have recently been spent on investigating the impact of and developing methods to improve the temporal representation, the spatial resolution and the representation of operational constraints.

The temporal representation is the central focus in Deane et. al. [8] in which the authors investigate the impact of adopting a sub-hourly temporal representation in a unit-commitment and economic dispatch model. Pina, Silva \& Ferrão [9] show that enhancing a typical long-term energy-system optimization model with a short-term operational model in an iterative manner improves model accuracy, especially when there is limited storage capacity available. Furthermore, Haydt et.al. [10] investigate the importance of capturing the dynamics of several intermittent renewable energy sources in long-term planning models. They point out that renewable generation can be substantially overestimated if these dynamics are not properly accounted for. Besides iterative approaches [9], other approaches have been proposed to improve the temporal representation in long-term planning models, such as the selection of representative historical periods. Nahmmacher et. al. [11] use a clustering algorithm to group similar historical days together and select one of them to represent each cluster. Poncelet et. al. [12] propose an optimization tool for selecting representative days that best capture the annual load and RES-duration curves. To determine the effect of the spatial resolution, Simoes et.al. [13] compare results from planning models in which the Austrian power system is represented by various numbers of wind and solar regions. Finally, the impact of the level of technical detail is investigated in [14-18]. The analysis in [14] uses the soft-linking approach proposed in [18] to compare planning models with low and high technical details. A similar analysis is conducted by Welsch et. al. [15], which use this soft-linking approach as benchmark against which the enhanced operational detail in planning models is measured. Finally, Palmintier \& Webster $[16,17]$ propose a clustered unit commitment approach to include operational constraints in planning models.

In contrast to the level of temporal, spatial and operational detail, limited attention has gone to the impact of the geographical scope of long-term planning models. In practice, many energy-system optimization models in Europe are directly developed to provide policy support for a single country, and have a geographical scope directly corresponding to the country on which is focused. Examples are for instance the Belgian [3], Danish [19], British [20], Swedish [21], Portuguese [22] and Irish [23] TIMES models.

At the same time, it has been widely recognized that highly interconnected networks can form an important provider of flexibility in future electricity systems [24-26]. Indeed, Von Bremen [24] shows that in interconnected electricity systems, the variability and uncertainty related to renewable electricity generation can be significantly reduced due to spatial smoothing. Furthermore, Heide et. al. [25] exploit this effect to determine the optimal shares of wind and solar PV in a 100\% renewable scenario and its implications on storage needs. Schlachtberger et. al. [26] investigate the benefits of having a more interconnected European power system, as opposed to having more regionally balanced storage-based systems in case of high renewable shares. They demonstrate that as the degree of interconnection increases, average system costs decrease in a non-linear 
manner. The same finding was obtained by Li et. al. [27]. Furthermore, Frew \& Jacobson [28] investigate the impact of several model features on planning outcomes, one of which is the geographical scope. The authors compare the total system cost and excess renewable generation for an isolated and interconnected setting of the Western Electricity Coordinating Council regions (WECC regions). They also conclude that in systems with stringent renewable targets interconnectors substantially reduce the total system cost and renewable overgeneration. In their 2018 review paper on state-of-the-art generation expansion problems, Koltsaklis \& Dagoumas [29] highlight the importance of considering all supply side options, including electricity trade, as a key aspect likely to have significant impacts on model results. They furthermore stress that an integrated generation and transmission expansion planning exercise improves the optimality of planning exercises. All these considerations highlight the importance of properly capturing the value and flexibility that can be offered by interconnected networks in the form of cross-border trade (CBT) opportunities in long-term planning models.

Different approaches have been used in different existing models to account for trade opportunities between the country/region of focus and the outside world. A first approach would be to extend the model scope to cover a larger area than the focus country/region. This is done for instance in the first version of NREL's resource planning model. This model focuses on the state of Colorado and has a high spatial resolution to represent load distributions and differences in renewable resource quality. Interestingly, the model scope is extended beyond the state of Colorado by explicitly considering neighboring states Wyoming, Utah and New Mexico [30], albeit at a lower spatial resolution. In a similar philosophy, national energy system models of European countries could extend their geographical scope to explicitly represent (the electrical power sector of) neighboring countries. Examples of this can be found in [31-33]. The holistic approach presented in [31] includes a system planning optimization for the German energy system which takes into account interconnections with the neighboring countries. Pattupara \& Kannan [32] perform a planning exercise for the Swiss power system using the Cross-border Swiss TIMES Electricity Model (CROSSTEM). CROSSTEM is a multi-region model in which Switzerland is treated as the focus area, while the five neighboring countries are included to endogenously represent electricity trading. In addition, the model can trade electricity with an external fringe representing the countries that lie beyond the Switzerland's direct neighbors. Finally, the authors of [33] iterate a European-wide investment model (including endogenous representation of crossborder trade) with a detailed load flow based grid model to obtain cost optimal investment decisions in generation as well as transmission assets.

A second commonly used approach to represent opportunities for cross-border trade of electricity is to use exogenously defined cross-border trade functions, i.e., exogenously defined import/export price-quantity pairs (see e.g., the Belgian TIMES model [34], the Danish TIMES model [19]). These functions aim to reflect the quantity of electricity that can be traded at a particular moment and at which price it can be traded. As an example, the Belgian TIMES model used in [34] uses a stepwise import function where each GW of import capacity can be used at a different price. The import prices increase as electricity imports increase and are derived from day-ahead market prices for all neighboring countries. The mathematical description of these import/export curves are clearly described by Koltsaklis et.al. in $[35,36]$, where import and export blocks are used to trade electricity. Each block defines a price-quantity pair that represents a specific import/export capacity and an import/export cost. From a computational perspective, the benefit of this approach is that all countries/regions excluded from the optimization are fully parametrized, meaning that no variables are required to endogenously determine the capacity mix in these countries, leading to a substantial decrease in computational effort. However, in practice, these import/export curves are typically derived ad hoc, and, to the best of the authors' knowledge, the current literature does not describe guidelines for creating these cross-border trade functions or a validation of the use of cross-border trade functions. Furthermore, since the values for the import/export prices typically are derived from data in the neighboring countries, and since cross-border trade flows should be valued based on the domestic electricity price, an ex-post re-evaluation of the cost of import/export is required.

This paper aims to contribute to the current literature in three ways.

1. First, this paper assesses the impact of using a single-country model for long-term planning in cases 
where the electricity system is interconnected in reality. To this end, an investment planning model for central-western Europe is developed and used to investigate the impact of neglecting cross-border trade opportunities for different scenarios. For each scenario we compare planning model outcomes (welfare and technology choices) from a model that ignores cross-border trade and one that endogenously incorporates all neighboring countries. This analysis is different from previous studies, as the focus in this paper is specifically on domestic welfare and technology choices, whereas the current literature focuses on the overall benefits that can be achieved through interconnecting electricity networks. Furthermore, we draw attention to the congestion rent that needs to be considered as a welfare component when looking at the country-level impact of trade on welfare.

2. Second, we put forward three novel methods to represent cross-border trade opportunities in long-term planning models. The first involves extending the geographical scope and including the foreign dispatch decisions in the neighboring countries (as in e.g., [30-33]), while fixing the foreign capacity variables in line with pre-designed scenarios for those countries. The second method involves using import and export curves to represent each country's trade opportunities (as in e.g., $[19,34,36]$ ) that are carefully designed based on exogenous capacity mix scenarios for the neighboring countries. Finally, the third method also uses import and export curves. However, contrary to the second method, we design them using a stylized approach. The main difference between methods two and three is that the import and export curves used in the second method are carefully designed for each time step individually, whereas the third method uses a single import and export curve for all time steps based on annual average import/export potentials.

3. Third, we evaluate the proposed methods in terms of accuracy, computational performance and convenience. In doing so, we contribute to the existing literature by explicitly formulating guidelines with regards to usage and interpretation of the methods described above. Furthermore, current literature (for example in $[37,38]$ ) does often not include a detailed description of how the representation of crossborder trade is treated. As such, this paper could serve as a reference for the treatment of cross-border trade representation in planning models with a limited geographical scope.

As will be shown in the remainder of this paper, accounting for interconnections clearly affects technology choices due to geographical effects like spatial smoothing of renewables. Furthermore, it is shown that the welfare for the focus country/region increases substantially for systems with high renewable penetrations if cross-border trade opportunities are included. However, whether these welfare gains appear as real reductions in operational and capital costs or as congestion rents depends strongly on the available transmission capacity. Also, we find that the welfare of the total system increases as the available transmission capacity increases. In addition, including foreign dispatch decisions in the optimization is proven to be the most accurate method. By properly designing the cross-border trade curves following the proposed novel method computation time can be decreased, but the model outcomes become less accurate. As such, this paper presents new insights and clear guidelines that are of relevance for the modeling community concerned with long-term planning.

The remainder of the paper is structured as follows: Section 2 illustrates the complexity of representing crossborder trade opportunities in planning models with a restricted geographical scope, and derives requirements for methods to do so. Next, Section 3 introduces the methodology used to analyze the impact of cross-border trade on domestic planning model outcomes and presents the two novel methods proposed in this paper. Subsequently, Section 4 presents and discusses the results. Finally, the conclusions are listed in Section 5.

\section{Requirements for methods representing trade opportunities}

This section aims to derive requirements for methods to represent cross-border trade opportunities in geographically constrained long-term planning models. A simplified two-country system, as depicted in Figure 1 , is used in this regard.

For data inspired by the Belgian and French system Figure 2a shows the marginal generation cost and the excess generation potential in country $\mathrm{B}$ as a function of time. In addition, Figure $2 \mathrm{~b}$ presents the marginal 


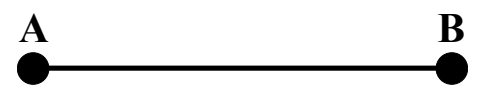

Figure 1: An illustrative 2-country system

generation cost in country B as a function of the residual demand in country A.

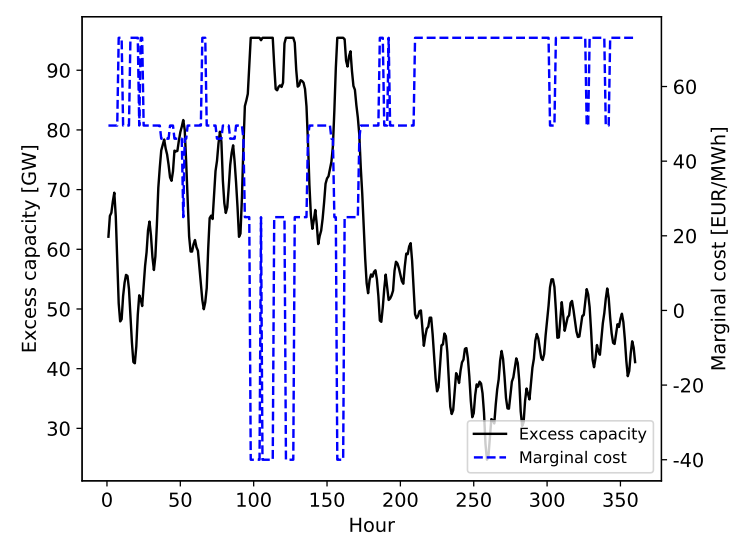

(a)

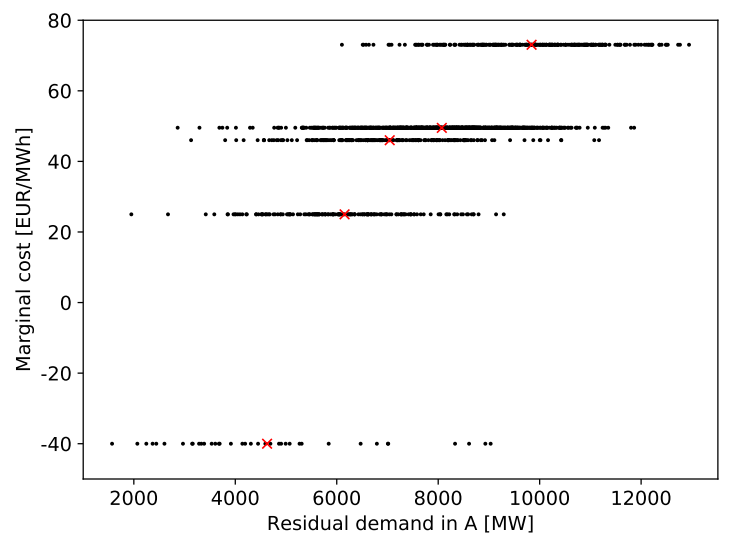

(b)

Figure 2: (a) The total excess generation capacity and the marginal cost of generating electricity in country $\mathrm{B}$ for a selected time window. (b) The marginal cost of generating electricity in country $\mathrm{B}$ against the residual demand in country A for all hourly data points.

From these figures two effects stand out. First, it can be seen that both the potential to import, and the cost of the imported electricity is highly time dependent. This results from the fact that there are short-term variations in the load, and the availability of (renewable) generators to generate electricity. Furthermore, trade opportunities will also vary over the course of the considered planning horizon due to changes in the capacity mix and the load profile. Hence, the cross-border trade opportunities also vary from milestone year to milestone year. As a result, a first requirement for methods to represent cross-border trade opportunities is to reflect both long and short-term changes in the potential and the cost/price at which electricity can be traded. Although import prices often are differentiated over time, the available import capacity does not (see e.g., $[19,34,37,38]$ )

Second, Figure $2 \mathrm{~b}$ shows a clear relation between the residual demand (i.e., the load subtracted by the generation of variable renewable energy sources) in country A and the cost at which electricity can be imported. While hours of low residual demand can benefit from imports from cheaper resources, hours of high residual demand cannot. This is a result of the geographic correlations between electricity consumption, and renewable generation. For example, moments characterized by high demand and low renewable generation in A, are likely to be moments of high demand and low renewable generation in B as well. Similarly, when demand is high and renewable generation is low in A it is likely that country B exhibits the same situation. Hence, a second requirement for a method to represent cross-border trade opportunities in long-term planning is to capture the fact that cross-border trade opportunities exhibit a certain correlation with the domestic electricity needs. 


\section{Methodology}

\subsection{Assessing the impact of accounting for cross-border trade}

First and foremost, this paper aims to assess the importance of correctly representing cross-border trade opportunities in long-term energy-system optimization models with a limited geographical scope, as opposed to neglecting these opportunities.

As basis for our analyses we take the interconnected Central-Western European power system (CWE), including Belgium, The Netherlands, Germany, France and The United Kingdom (Figure 3). Using Belgium as the focus area, we compare Belgian planning model outcomes obtained from (i) a planning model in which Belgium is isolated, i.e., there are no interconnections taken into account (referred to as 'Isolated') and (ii) a planning model in which Belgium is interconnected and the investments in all countries are co-optimized (referred to as 'Interconnected').

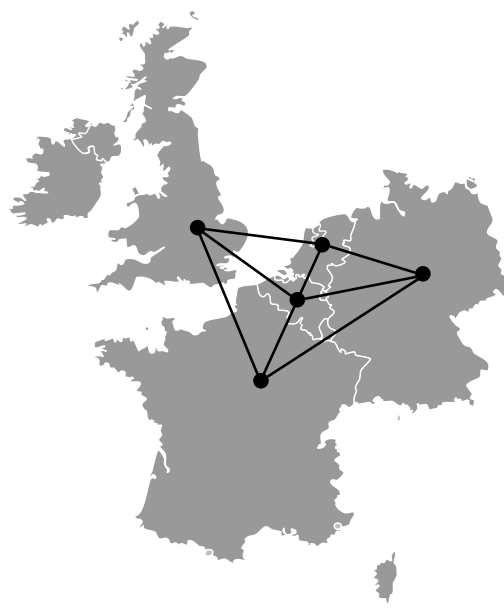

Figure 3: The interconnected central-western European power system.

Note that the CWE system as represented in the interconnected case represents a coupled electricity market in which transmission capacity is implicitly allocated. This means that we assume that all cross-zonal transmission capacity is allocated in the day-ahead time frame. As such, we do not consider transmission capacity allocated to longer-term time frames.

\subsubsection{Scenarios and input data}

In order to illustrate the impact for different situations, we compare the planning model outcomes for three different scenarios. The first scenario is a greenfield scenario in which no legacy capacity is included. Furthermore, the 2020 RES-targets for each country's electricity sector are imposed. This Greenfield 2020 scenario represents the case in which countries engage in a full co-operation in order to pursue total system cost minimization. As such, it is a scenario in which investments fully exploit the geographically varying renewable potentials and their correlations.

It has to be stated that in reality, it is unlikely that such a perfect co-operation materializes. This is why also a Brownfield 2020 scenario is included. In this scenario we introduce legacy capacity in all neighboring countries equal to $80 \%$ of the technology taking up the largest share in the current capacity mix (see Table 2). Hence, this scenario resembles a situation in which the surrounding power systems are characterized by different technologies. As a result, the investment decisions taken in this scenario exploit, besides the variations in renewable potentials, also the geographical effects related to this difference in power system structure. 
Finally, also a Greenfield HRES scenario is included in which the RES targets are strengthened to twice the 2020 targets. As such, this scenario illustrates a case with large renewable penetrations. Tables 1 and 2 summarize all three scenarios.

\begin{tabular}{ccc} 
& Foreign capacity legacy & Policy \\
\hline Greenfield 2020 & None & 2020 targets \\
Brownfield 2020 & $\begin{array}{c}\text { 80\% of largest existing technology } \\
\text { included as capacity legacy }\end{array}$ & 2020 targets \\
Greenfield HRES & None & $2 \times 2020$ targets \\
\hline
\end{tabular}

Table 1: Summary of the three different scenarios assessing the impact of accounting for cross-border trade.

\begin{tabular}{ccc} 
Country & $\begin{array}{c}\text { 2020 RES target for } \\
\text { electricity sector [\%] } \\
{[\mathbf{3 1}]}\end{array}$ & $\begin{array}{c}\text { Brownfield capacity } \\
\text { legacy }\end{array}$ \\
\hline Belgium & 20.9 & - \\
The Netherlands & 37 & CCGT $-12.46 \mathrm{GW}$ \\
Germany & 38.6 & Coal $-37.20 \mathrm{GW}$ \\
France & 27 & Nuclear $-50.50 \mathrm{GW}$ \\
The United Kingdom & 31 & CCGT $-28.92 \mathrm{GW}$ \\
\hline
\end{tabular}

Table 2: Summary of the national 2020 targets and the capacity legacy used in the brownfield 2020 scenario.

Table 3 presents the assumed interconnection capacities between the different countries. Values correspond to the 2020 net transfer capacities (NTC) from the 2018 edition of ENTSO-E's TYNDP [39]. Furthermore, Table 4 lists all technology related costs and efficiencies, which are based on [40].Demand and renewable profiles are taken from ENTSO-E's transparency platform for the year 2018 and all scenarios include a carbon price of $25 € /$ ton $\mathrm{CO}_{2}$. All planning models adopt a temporal representation spanning a full year with an hourly resolution.

\begin{tabular}{cccc} 
Interconnection & NTC $[$ MW] & Interconnection & NTC $[$ MW] \\
\hline $\mathbf{B E} \rightarrow \mathbf{~ N L}$ & 2400 & $\mathbf{N L} \rightarrow \mathbf{B E}$ & 1400 \\
$\mathbf{B E} \rightarrow \mathbf{D E}$ & 1000 & $\mathbf{D E} \rightarrow \mathbf{B E}$ & 1000 \\
$\mathbf{B E} \rightarrow \mathbf{F R}$ & 1800 & $\mathbf{F R} \rightarrow \mathbf{B E}$ & 3300 \\
$\mathbf{B E} \rightarrow \mathbf{U K}$ & 1000 & $\mathbf{U K} \rightarrow \mathbf{B E}$ & 1000 \\
$\mathbf{N L} \rightarrow \mathbf{D E}$ & 4250 & $\mathbf{D E} \rightarrow \mathbf{\text { NL}}$ & 4250 \\
$\mathbf{N L} \rightarrow \mathbf{U K}$ & 1000 & $\mathbf{U K} \rightarrow \mathbf{\text { NL}}$ & 1000 \\
$\mathbf{F R} \rightarrow \mathbf{D E}$ & 1800 & $\mathbf{D E} \rightarrow \mathbf{F R}$ & 2300 \\
$\mathbf{F R} \rightarrow \mathbf{U K}$ & 2000 & $\mathbf{U K} \rightarrow \mathbf{F R}$ & 2000 \\
\hline
\end{tabular}

Table 3: 2020 NTC values for the Interconnections between the considered countries taken from [39].

\begin{tabular}{cccccc} 
Technology & $\begin{array}{c}\text { Investment cost } \\
{[\mathbf{E U R} / \mathbf{k W}]}\end{array}$ & $\begin{array}{c}\text { FOM } \\
{[\mathbf{E U R} / \mathbf{k W} / \mathbf{a}]}\end{array}$ & $\begin{array}{c}\text { VOM } \\
{[\mathbf{E U R} / \mathbf{M W h}]}\end{array}$ & $\begin{array}{c}\text { Fuel } \\
{\left[\mathbf{E U R} / M W h_{p}\right]}\end{array}$ & $\begin{array}{c}\text { Efficiency } \\
{[\%]}\end{array}$ \\
\hline Coal & 1320.5 & 20.1 & 3.0 & 10 & 39 \\
CCGT & 887.1 & 25.8 & 2.4 & 20 & 51 \\
OCGT & 611.5 & 12 & 2.4 & 20 & 34 \\
Onshore wind & 2288.5 & 48.9 & 0 & 0 & - \\
Solar PV & 1794.3 & 0 & 0 & 0 & - \\
\hline
\end{tabular}

Table 4: Generation technology costs and efficiencies based on [40]. 


\subsubsection{Domestic welfare calculation}

Since the aim is to compare the domestic welfare of a country between the Isolated and Interconnected situations, some elaboration is required on how the domestic welfare is calculated. To illustrate the domestic welfare calculations, consider again the two country system from Section 2. Suppose that country A is characterized by a low demand $\left(D_{A}\right)$ and low marginal generation costs $\left(M C_{A}\right)$, while country $\mathrm{B}$ is characterized by a high electricity demand $\left(D_{B}\right)$ and high marginal generation costs $\left(M C_{B}\right)$. Furthermore, assume that country A exports a quantity $f$ to country B, as shown in Figure 4, and that the transmission line in this situation is congested, so that the electricity prices in $\mathrm{A}\left(\lambda_{A}\right)$ and $\mathrm{B}\left(\lambda_{B}\right)$ do not converge.

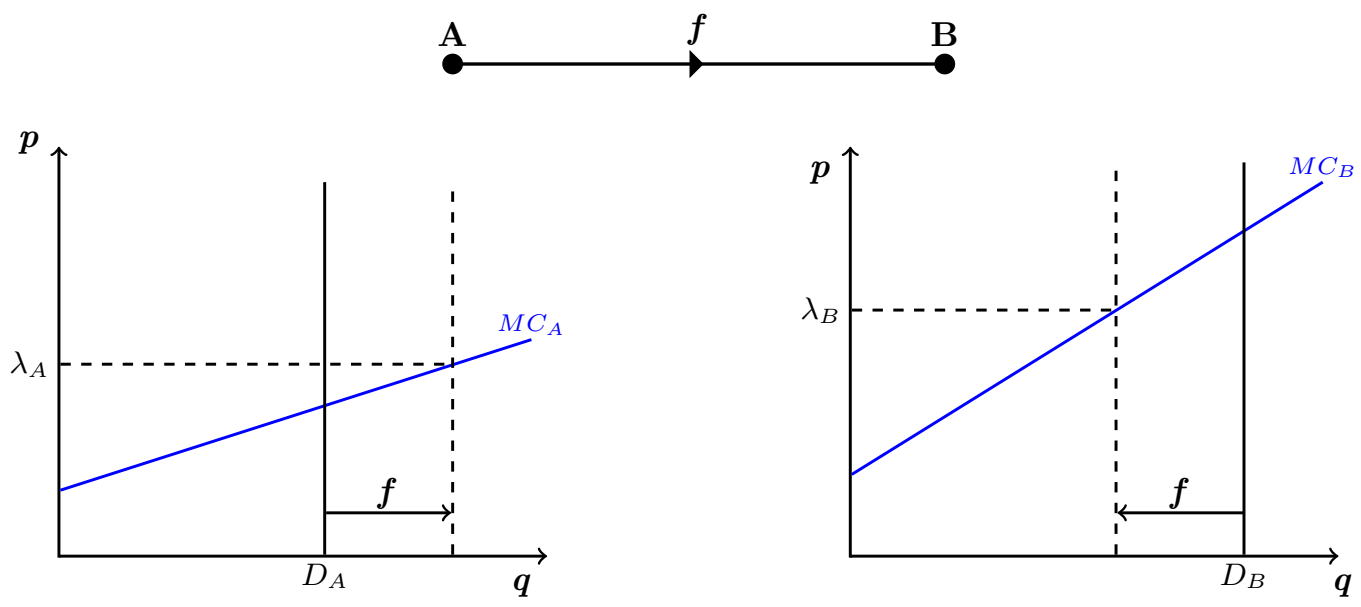

Figure 4: A two-country system. Country A is characterized by low demand and low generation costs. Country B is characterized by high demand and high generation costs.

The aim of a planning model is to maximize total welfare. As such, for our two-country example the sum of the social welfare (SW) in country A and in country B is maximized as follows:

$$
\begin{aligned}
& \max S W_{A}+S W_{B} \\
& \text { with } S W_{A}=C S_{A}+P S_{A}+\frac{C R}{2} \\
& S W_{B}=C S_{B}+P S_{B}+\frac{C R}{2}
\end{aligned}
$$

Equations (1) and (2) indicate that the social welfare of a country that trades electricity consists of (i) a consumer surplus (CS), (ii) a producer surplus (PS) and (iii) a portion of the congestion rent $(\mathrm{CR})^{1}$. These welfare components are shown in Figure 5 for both countries. The dark grey areas represent the consumer surpluses, the light grey areas represent the producer surpluses and the blue area represents the congestion rent.

\footnotetext{
${ }^{1}$ Typically, cross-border interconnections are jointly operated and maintained by the TSOs active in both countries. As such, we assume that the congestion rents are distributed equally between the interconnected countries.
} 

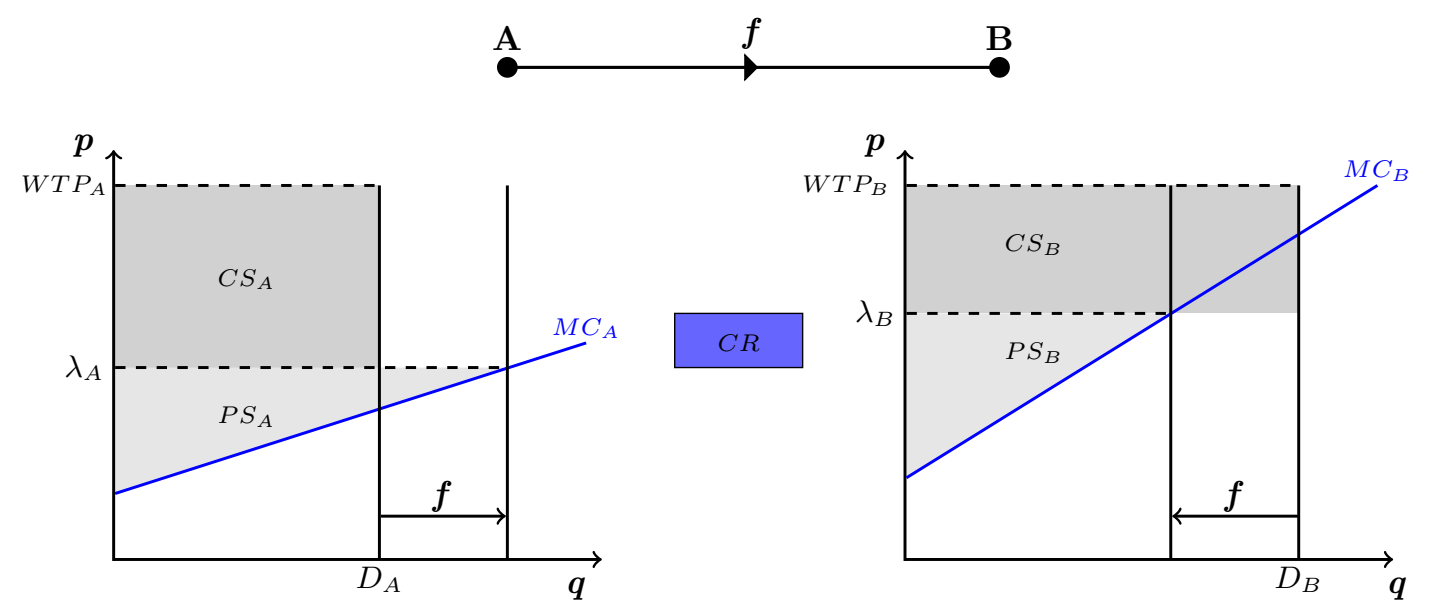

Figure 5: The different welfare components for countries A and B.

From Figure 5, it is straightforward to see that the social welfare of country A can be written as follows:

$$
S W_{A}=\underbrace{\int_{0}^{D_{A}}\left(W T P_{A}-\lambda_{A}\right) \cdot d q}_{C S_{A}}+\underbrace{\int_{0}^{D_{A}+f}\left(\lambda_{A}-M C_{A}\right) \cdot d q-C A P E X_{A}}_{P S_{A}}+\underbrace{\frac{\left(\lambda_{B}-\lambda_{A}\right) \cdot f}{2}}_{C R / 2}
$$

Note that in equation (3) the producer surplus also contains the capital expenditures (CAPEX) related to the investments in generation assets (not shown in Figure 5). Expanding the integrals and rearranging terms gives:

$$
S W_{A}=\underbrace{\int_{0}^{D_{A}} W T P_{A} \cdot d q}_{\text {Consumer value }}-(C A P E X_{A}+\underbrace{\left.\int_{0}^{D_{A}+f} M C_{A} \cdot d q\right)}_{\text {Operational expenditures }}+\lambda_{A} \cdot f+\frac{\left(\lambda_{B}-\lambda_{A}\right) \cdot f}{2}
$$

The first term of Equation 4 represents the consumer value (CV) of the electricity consumed in A. The second term represents the total production cost for country A and it consists of the country's CAPEX and the operational expenditures (OPEX) of the electricity generated in A. The third term reflects the value of the exported electricity or export value. Finally, the fourth term indicates the share of the congestion rent that is allocated to country A. Hence, Equation (4) can be written as:

$$
S W_{A}=C V_{A}-\left(C A P E X_{A}+O P E X_{A}\right)+\lambda_{A} \cdot f+\frac{\left(\lambda_{B}-\lambda_{A}\right) \cdot f}{2}
$$

Performing the same derivation for country B results in an almost identical expression. The only difference is that the third term does not represent an export value, but an import cost (IC). The social welfare of country B can be written as:

$$
S W_{B}=C V_{B}-\left(C A P E X_{B}+O P E X_{B}\right)-\lambda_{B} \cdot f+\frac{\left(\lambda_{B}-\lambda_{A}\right) \cdot f}{2}
$$

Equations (5) and (6) show that the social welfare in a country consists of (i) a consumer value, (ii) a production cost containing CAPEX as well as OPEX, (iii) a component related to electricity trade and (iv) a congestion rent. Since we use inelastic electricity demands the consumer value is a constant term and hence does not change. As such, changes in the social welfare can only result from changes in the production cost, the cost/revenue of electricity trade and the congestion rent. In the remainder of this paper, we will report 
and analyze changes in a country's welfare based on these welfare components.

Note that the total welfare we want to maximize does not contain any terms related to electricity trade or congestion rents. Indeed, adding Equations (5) and (6) gives:

$$
S W_{A}+S W_{B}=C V_{A}+C V_{B}-\left(C A P E X_{A}+O P E X_{A}+C A P E X_{B}+O P E X_{B}\right)
$$

Again, since we assume inelastic electricity demands, the consumer values constitute a constant term. Hence, maximizing Equation (7) is equivalent to minimizing the positive sum of the CAPEX and OPEX in all countries. As such, the planning models we use in this paper adopt this cost minimization approach.

\subsection{Methods to model cross-border trade}

In addition to the assessment of the impact of capturing cross-border trade opportunities, three methods to represent cross-border trade opportunities are formulated and investigated. The first entails constructing scenarios for the evolution of the capacity mix in the neighboring countries and fixing the investment variables in line with these scenarios while keeping the foreign dispatch decisions endogenous to the model, i.e., investment and operational decisions in the focus region are co-optimized with operational decisions in the neighboring countries/regions. The second method also starts from exogenously determined scenarios for the capacity mix in neighboring countries/zones, but further reduces the computational cost by using this information to construct carefully tailored import and export curves for every time step. Finally, the third method uses a single import and export curve for all time steps based on annual average import/export potentials.

It has to stated that some elements of the proposed methods might seem familiar to the reader. However, the methods presented here comprise a coherent stepwise approaches that, to the best of the author's knowledge, has not been presented so far. Therefore, we consider these approaches to be novel methodologies that can serve as a reference for national planning purposes. Additionally, since current literature often does not include a detailed description of the treatment of cross-border trade, it is not unthinkable that often a highly stylized approach such as our third method is used. As such, this third approach is included in our analysis to assess the performance of these simplified methods.

\subsubsection{Endogenize foreign dispatch decisions}

The first method consists of 5 steps:

1. Construct scenarios for the evolution of the capacity mix and the electricity demand in neighboring countries/regions.

2. Expand the geographical scope of the model to span the power system of neighboring countries/regions.

3. Fix the installed capacities in neighboring countries/regions in line with the scenarios of step 1.

4. Solve the optimization model.

5. Re-evaluate the country-specific welfare to include all necessary welfare components.

The first step is to make assumptions about the evolution of the power system lay-out in the neighboring countries. These scenarios can be inferred from other planning studies specifically focusing on those countries, announced policy measures that signal the way in which the power systems could transition, or model runs with a (simplified) planning model or expert knowledge. This is an important difference with multicountry/region models that co-optimize investments in multiple countries/regions, and hence endogenously determine the installed capacities in the neighboring countries/regions. Two important notes need to be made here. First, it has to be noted that the aim of the presented methodologies is to improve the accuracy of models focusing on a single country/region of interest. These models have a different objective and are to be positioned complementary to optimization models that cover a large geographical area and co-optimize 
investments in several countries/regions. Second, it is important to note that every model is a simplified representation of reality. Hence, the endogenously made projections of the capacity mix in multi-country/region models are not necessarily better or worse than the exogenously made projections of the capacity mix in neighboring countries as proposed in this method. For instance, in certain cases, it might be beneficial to take the results from a dedicated study of a neighboring country/region that contains a lot of detail of that system and is performed by researchers aware of the specific situations and policies in that country/region.

It has to be stressed that the aim of these methodologies is to obtain more accurate results for only the focus country. It is not our intention to replicate a co-optimized system. Obviously, if one is concerned with planning a national system, one needs to acknowledge that what happens in the neighboring countries is beyond your control. Hence, co-optimization might not be the best strategy for domestic energy system planning, since it is unlikely that the power systems evolve in the same way as indicated by a co-optimization. For national planning purposes, the co-optimized system is nothing more than a very specific, ideal scenario representation. As such, generating accurate scenarios for the neighboring countries is an essential step in the planning of national energy systems.

In the second and third step, these assumptions are imposed on the planning model by (i) fixing the investment variables to the values characterizing the projected capacity mixes or (ii) by inserting these projections as capacity legacy. This leaves only the dispatch variables of the neighboring countries to be decided on endogenously by the model. As such, this approach results in coherent dispatch situations and cross-border trade flows given the projected capacity mixes. The optimization can be described mathematically as follows.

$$
\begin{array}{cr}
\min \sum_{c \in C} \sum_{g \in G} F C_{g} \cdot \operatorname{cap}_{c, g}+\sum_{t \in T} \sum_{c \in C} \sum_{g \in G} V C_{g} \cdot \operatorname{gen}_{c, g, t} \cdot \Delta T+\sum_{t \in T} \sum_{c \in C} \sum_{c^{\prime} \in C \backslash\{c\}} \Phi \cdot\left|\operatorname{trans}_{c, c^{\prime}, t}\right| \cdot \Delta T \\
\text { subject to } \sum_{g \in G} g e n_{c, g, t}=D_{c, t}+\sum_{c^{\prime} \in C \backslash\{c\}} \operatorname{trans}_{c, c^{\prime}, t} & \forall c \in C, \quad \forall t \in T \\
\operatorname{gen}_{c, g, t} \leq \operatorname{cap}_{g} & \forall c \in C, \quad \forall g \in G_{D}, \quad t \in T \\
\operatorname{gen}_{c, g, t} \leq C F_{c, g, t} \cdot \operatorname{cap}_{g} & \forall c \in C, \quad \forall g \in G_{R}, \quad t \in T \\
\operatorname{cap}_{c, g}=C A P_{c, g} & \forall c \in \bar{C}, \quad \forall g \in G, \quad t \in T \\
\operatorname{trans}_{c, c^{\prime}, t} \leq K_{c, c^{\prime}} & \forall c \in \bar{C}, \quad \forall c^{\prime} \in C \backslash\{c\}, \quad t \in T \\
\operatorname{trans}_{c, c^{\prime}, t}=- \text { trans }_{c^{\prime}, c, t} & \forall c \in \bar{C}, \quad \forall c^{\prime} \in C \backslash\{c\}, \quad t \in T
\end{array}
$$

The objective function expresses the total fixed costs and the total generation costs in all countries. In order to represent transmission losses we introduce a small transmission cost $\Phi$. It has to stressed that with this transmission cost, we do not primarily aim to model transmission losses in great detail. Instead, the main aim of this transmission cost is to differentiate between one MWh of electricity generated domestically and one MWh of electricity imported from a different country. This is necessary to avoid ambiguity in the in the resulting capacity mix. If we would not distinguish between domestic generation and foreign imports, the optimization model would have some freedom to geographically redistribute installed capacity while maintaining the same objective function value. Introducing the transmission cost ensures that the investments made in a particular country are made because in that country they contribute to a cost minimal solution.

Equation (8) expresses the power balance for all countries and every time step. Equations (9) and (10) represent the generation limits for respectively, dispatchable and renewable technologies $\left(C F_{g, t}\right.$ represents the time-varying capacity factor for renewable technologies). Equation (11) fixes the capacity variables of the neighboring countries in line with the designed scenarios (step 1) and Equation (12) limits the transmission flows to the available transmission capacity. Finally, Equation (13) links the transmission variables of different countries.

Finally, after having solved the optimization the domestic welfare needs to be extracted ex-post, by applying Equation (5) for the focus country. 


\subsubsection{Time step-dependent import and export curves}

This second method uses time-step dependent import and export curves, and can be summarized in 5 steps.

1. Construct scenarios for the evolution of the capacity mix and the electricity demand in neighboring countries/regions.

2. Construct cross-border trade functions that represent each trade country's/region's potential to export to the focus country/region and the willingness to import from the focus country/region for every time step individually.

3. Integrate the cross-border trade functions in the optimization model.

4. Solve the optimization model.

5. Re-evaluate the country-specific welfare to include all necessary welfare components.

As in the previous method, the first step entails the composition of capacity mix scenarios for all neighboring countries. However, in this method, this information is used to construct import and export functions instead of expanding the model's geographical scope and fixing the investment variables. The purpose of these functions is to represent (i) the potential of the neighboring countries to export electricity to the modeled country (import function) and (ii) the willingness of the neighboring countries to import electricity from the modeled country (export function).

Given the assumptions regarding the capacity mix and the electricity demand in the neighboring countries/regions, these functions can be constructed by using the countries' supply and demand curves (see Figure 6a). The demand in the neighboring countries divides the time-dependent supply curve in an import curve (reflecting the potential of the excluded country to generate electricity that can be imported by the focus country/region) and an export curve (reflecting the willingness to pay of the excluded country for electricity exported by the focus country/region) for a particular time step $t$. In the absence of cross-border trade, the technologies are being dispatched according to the merit-order up to the point at which supply and the demand are equal. All remaining technologies that are not being dispatched could potentially be used to import electricity from. Similarly, all the dispatched technologies could potentially be replaced by importing electricity from the focus country/region. Hence, assuming an inelastic ${ }^{2}$ demand for electricity, this demand in the neighboring countries/regions divides the supply curve in an import curve (reflecting the potential of the trade country to generate electricity that can be imported) and an export curve (reflecting the willingness to pay of the trade country for the exported electricity).

As Figure 6b indicates, the cross-border trade curves consist of a sequence of price-quantity pairs. Note that the quantities of each trade stage are time step dependent since both the demand and the electricity generated by intermittent renewable energy sources vary over time. In addition, if time-dependent fuel prices or taxes are used, also the price of each trade stage varies over time. Hence, each time step is characterized by a different import and export curve.

In the third step we incorporate the obtained import and export curves in the optimization model. The single-country optimization can be described mathematically as follows.

$$
\begin{aligned}
\min & \sum_{g \in G} F C_{g} \cdot \operatorname{cap}_{\tilde{c}, g}+\sum_{t \in T} \sum_{g \in G} V C_{g} \cdot g e n_{\tilde{c}, g, t} \cdot \Delta T+\sum_{t \in T} \sum_{c \in \bar{C}} \sum_{s \in S}\left(P_{c, s, t}^{i m p}+\Phi\right) \cdot i m p_{c, s, t} \cdot \Delta T \\
& -\sum_{t \in T} \sum_{c \in \bar{C}} \sum_{s \in S}\left(P_{c, s, t}^{\exp }-\Phi\right) \cdot \exp _{c, s, t} \cdot \Delta T
\end{aligned}
$$

\footnotetext{
${ }^{2}$ Note that the concept presented in Figure 6a can be extended to elastic demands.
} 


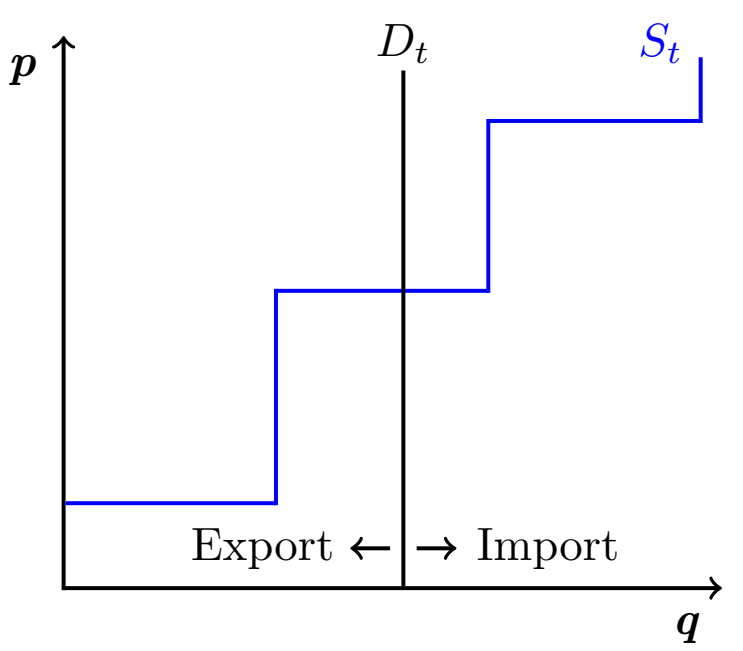

(a)

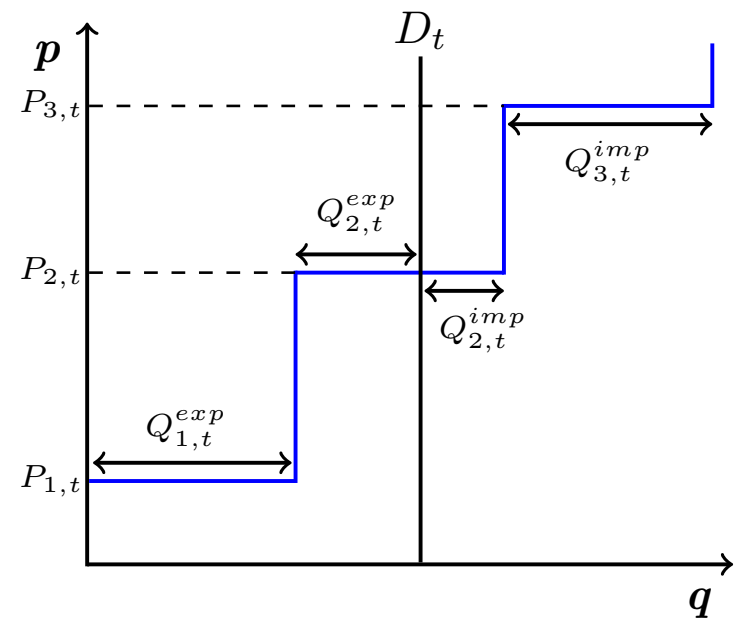

(b)

Figure 6: Illustration of the construction of time-dependent import en export curves: (a) The time-dependent demand divides the time-dependent supply curve in an import curve and an export curve. (b) Each import/export stage is characterized by a time-dependent price-quantity pair (that can be represented by a virtual technology with an available capacity and a marginal cost).

$$
\begin{aligned}
& \text { subject to } \sum_{g \in G} g e n_{\tilde{c}, g, t}+\sum_{c \in \bar{C}} \sum_{s \in S} i m p_{c, s, t}=D_{\tilde{c}, t}+\sum_{c \in \bar{C}} \sum_{s \in S} \exp _{c, s, t} \quad \forall t \in T \\
& \operatorname{gen}_{\tilde{c}, g, t} \leq \operatorname{cap}_{g} \quad \forall g \in G_{D}, \quad t \in T \\
& \text { gen }_{\tilde{c}, g, t} \leq C F_{g, t} \cdot \operatorname{cap}_{g} \\
& i m p_{c, s, t} \leq Q_{c, s, t}^{i m p} \\
& \exp _{c, s, t} \leq Q_{c, s, t}^{\exp } \\
& \forall g \in G_{R}, \quad t \in T \\
& \forall c \in \bar{C}, \forall s \in S, \quad t \in T \\
& \sum_{s \in S} i m p_{c, s, t} \leq K_{c}^{i m p} \\
& \forall c \in \bar{C}, \forall s \in S, \quad t \in T \\
& \forall c \in \bar{C}, \quad t \in T \\
& \sum_{s \in S} \exp _{c, s, t} \leq K_{c}^{e x p}
\end{aligned}
$$

The objective function comprises the total fixed and variable costs of every generator $g$ in the focus country as well as an import cost and an export revenue. Let $\left(P_{c, s, t}^{i m p} ; Q_{c, s, t}^{i m p}\right)$ represent the price-quantity pair that defines import stage s for neighboring country/region $c$ at time t, and let $\left(P_{c, s, t}^{\exp } ; Q_{c, s, t}^{\exp }\right)$ represent the price-quantity pair that defines export stage $s$ for trade country c at time $t$. In order to represent the cross-border trade curves in the objective function, each import/export stage is assigned a decision variable $\left(i m p_{c, s, t} / \exp _{c, s, t}\right)$ that represents the amount of electricity imported/exported for the specific stage at time $t$. The value of import is expressed by multiplying the imported quantity from each stage and the price of that stage. Similarly, the value of the exported quantity is obtained through the price of the used export stage. Again, we introduce the dummy transmission cost $\Phi$ to eliminate randomness due to ambiguous dispatch situations.

Equation (14) expresses the power balance for the modeled country/region for every time step. Equations (15) and (16) represent the generation limits for respectively, dispatchable and renewable technologies. The imported and exported quantities for each stage are limited to the stage cap by constraints (17) and (18), while the total flow over the transmission lines are restricted by the transmission network capacity by constraints (19) and (20). 
A drawback of this approach is that only the direct interconnections between the neighboring countries/regions and the focus country/region are included in the model. The interconnections between two neighboring countries are not modeled explicitly and will affect planning model outcomes, as will be discussed later. A second difficulty emerges if one introduces intertemporal constraints (required if one wants to add technical aspects, e.g., minimum up- and down times, or if storage technologies are included). These intertemporal aspects can pose challenges for an accurate cross-border trade curve design.

Numerical example - Consider a power system with three generators, one intermittent renewable and two dispatchable generators (one baseload and one peakload generator), at two different time steps (see Table 5 ). The first time step is characterised by high renewable generation and low demand, while the second time step is characterised by low renewable generation and high demand. We can construct the import and export curve by first constructing the supply curve by stacking the technologies according to the merit-order, and then using the demand to divide the supply curve in an import and an export part.

\begin{tabular}{ccc|c} 
& Capacity at $\mathrm{t}=1[\mathrm{MWh} / \mathrm{h}]$ & Capacity at $\mathrm{t}=2[\mathrm{MWh} / \mathrm{h}]$ & $\mathrm{MC}[\mathrm{EUR} / \mathrm{MWh}]$ \\
\hline \hline RES & 1000 & 100 & 0 \\
\hline Base & 1000 & 1000 & 40 \\
\hline Peak & 500 & 500 & 70 \\
\hline Demand & 900 & 1500 & - \\
\hline
\end{tabular}

Table 5: Power system characteristics during two different time steps.

Tables 6 and 7 summarize the price-quantity pairs for each stage in the import/export curves in the first and second time step respectively. as can be seen, there is plenty of excess capacity during time step 1 which results in an extensive import curve, i.e., a total of $1600 \mathrm{MW}$ can be imported from the considered power system at costs ranging from 0 to $70 \mathrm{EUR} / \mathrm{MWh}$. At the same time, the potential to export to the power system at hand is rather low, i.e., only $900 \mathrm{MW}$ can be exported at a willingness-to pay of $0 \mathrm{EUR} / \mathrm{MWh}$.

For the second time step the opposite is true. Due to the low renewable generation and the high demand the potential of the power system to facilitate electricity imports is low. Indeed, only $100 \mathrm{MW}$ of the expensive peakload technology can be used to import electricity from. On the contrary, the potential to export is rather high. A total of $1500 \mathrm{MW}$ canbe exported with a willingness-to-pay ranging from 0 to $70 \mathrm{EUR} / \mathrm{MWh}$.

\begin{tabular}{ccc|cc}
$s$ & $Q_{s}^{i m p}$ & $P_{s}^{i m p}$ & $Q_{s}^{\exp }$ & $P_{s}^{\text {exp }}$ \\
\hline 1 (RES) & 100 & 0 & 900 & 0 \\
\hline 2 (Base) & 1000 & 40 & 0 & 40 \\
\hline 3 (Peak) & 500 & 70 & 0 & 70
\end{tabular}

\begin{tabular}{ccc|cc}
$s$ & $Q_{s}^{i m p}$ & $P_{s}^{i m p}$ & $Q_{s}^{\exp }$ & $P_{s}^{\exp }$ \\
\hline 1 (RES) & 0 & 0 & 100 & 0 \\
\hline 2 (Base) & 0 & 40 & 1000 & 40 \\
\hline 3 (Peak) & 100 & 70 & 400 & 70 \\
\hline
\end{tabular}

Table 6: Price-quantity pairs reflecting the import and export curves at time step 1.

Table 7: Price-quantity pairs reflecting the import and export curves at time step 2.

\subsubsection{Annual average import and export curves}

The third and final method consists roughly of the same 5 steps as the method from section 3.2 .2 with the difference that in step 2 the cross-border trade curves are not differentiated over time. Instead, a single import and export curve are designed based on the annual average cross-border trade potentials. As Figure 7 a illustrates, the annual average demand is used to divide the annual average supply curve in an import and export curve. This results in price-quantity pairs that are not time step dependent (Figure $7 \mathrm{~b}$ ). So that the price-quantity pairs lose their time index, i.e., $\left(P_{c, s}^{i m p} ; Q_{c, s}^{i m p}\right)$ and $\left(P_{c, s}^{e x p} ; Q_{c, s}^{e x p}\right)$. 


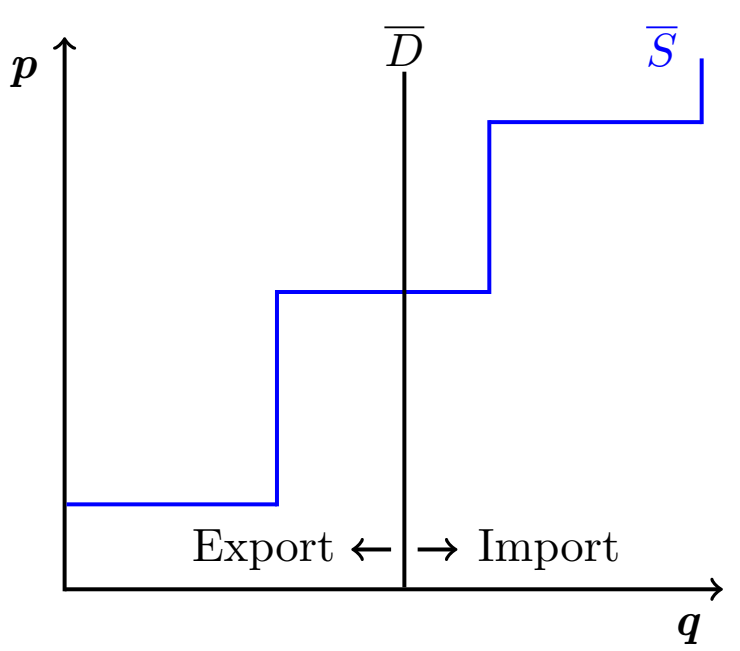

(a)

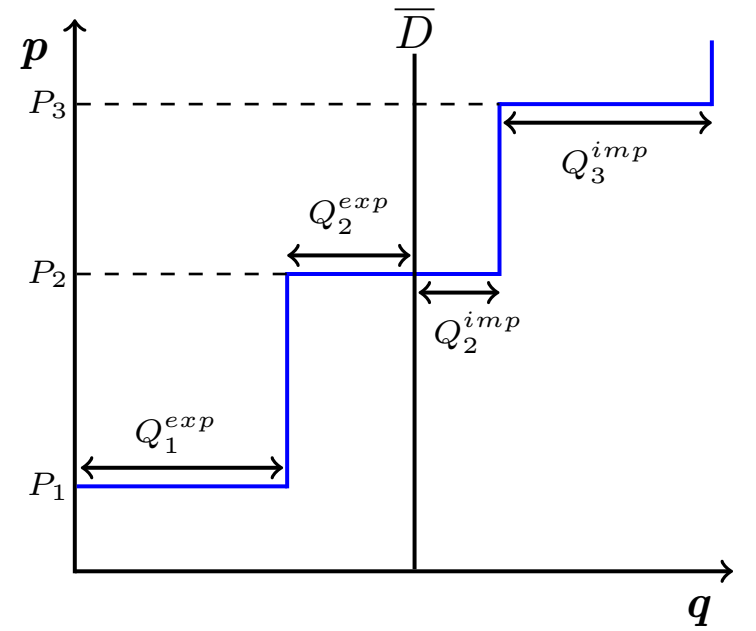

(b)

Figure 7: Illustration of the construction of annual average import en export curves: (a) The average demand in the neighboring countries divides the average supply curve in an import curve and an export curve. (b) Each import/export stage is characterized by a single price-quantity pair.

\section{Results}

First, Section 4.1. analyzes the impact of neglecting cross-border trade opportunities in long-term planning models. To this end, the results of a planning model of an isolated Belgium is compared to the results of a planning model in which Belgium is part of an interconnected system. Next, Section 4.2 analyzes the accuracy and the computational performance of the novel proposed methods to represent cross-border trade opportunities.

\subsection{Impact of a restricted geographical scope}

\subsubsection{Impact on domestic technology choices}

The obtained domestic capacity mixes in both the isolated and interconnected settings are shown in Figure 8 for all three scenarios. A first aspect that stands out from this graph is that there are significant differences in the investments in renewable energy technologies. A likely explanation may be that an interconnected system is able to exploit geographical variations in RES generation profiles to smooth the overall variability of intermittent renewable output. As such, in every country one RES technology gains a comparative advantage over the other when interconnections are introduced. For the neighboring countries, Tables 8 and 9 present the wind and solar capacities in the Greenfield 2020 and Brownfield 2020 scenarios. It can be seen that as interconnections are introduced, German wind and French solar PV gain a comparative advantage as a result of their complementarity in smoothing the overall renewable output. ${ }^{3}$ For Belgium, the interconnected setting consistently exhibits more solar PV relative to the isolated case. This is a result of wind being the dominant technology in the other countries, leading to domestic wind being less attractive.

\footnotetext{
${ }^{3}$ The adopted costs and renewable potential prevent solar PV to emerge in The Netherlands and The United Kingdom. Therefore, it is not straightforward to indicate which technology gains a comparative advantage in these countries.
} 


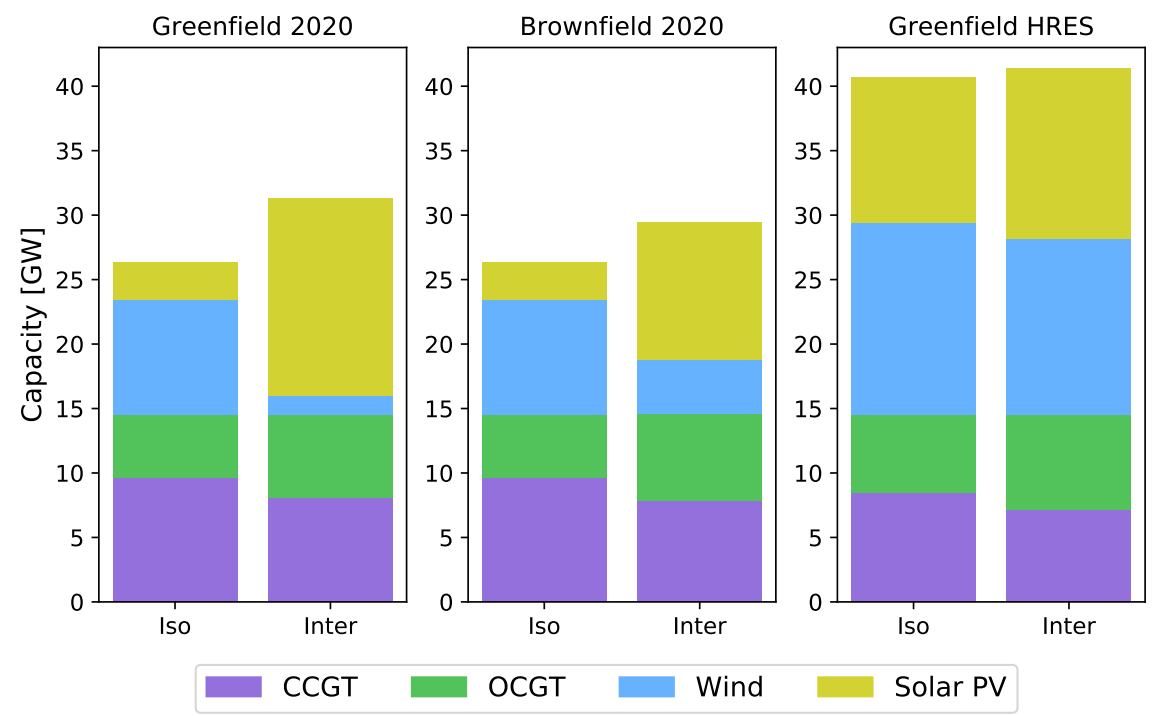

Figure 8: The domestic technology choices obtained by (i) ignoring cross-border trade opportunities (Iso) and (ii) explicitly modeling cross-border trade flows (Inter) for the three different scenarios.

The comparative advantage of PV is most apparent in the Greenfield 2020 scenario, but gets weakened in the Brownfield 2020 and Greenfield HRES scenario as a result of changes in the foreign capacity mixes. The Brownfield 2020 scenario is characterized by less harmonized capacity mixes (i.e., nuclear in France, coal in Germany) with respect to the greenfield 2020 scenario. Hence, besides the geographical variations in RES there is a different geographical effect that impacts planning model outcomes, namely the composition of the conventional capacity mix. In Greenfield HRES scenario the comparative advantage of PV is weakened by the fact that the more ambitious RES targets force PV in the neighboring countries to take a more prominent role (see Table 10). The PV generation profiles being highly correlated, decrease the contribution Belgian $\mathrm{PV}$ can make to lowering total system costs.

\begin{tabular}{|c|c|c|c|c|c|c|c|c|}
\hline \multirow{2}{*}{ Greenfield 2020 } & \multicolumn{2}{|c|}{ NL } & \multicolumn{2}{c|}{ FR } & \multicolumn{2}{c|}{ DE } & \multicolumn{2}{c|}{ UK } \\
\cline { 2 - 9 } & $\begin{array}{c}\text { Iso } \\
{[\mathbf{G W}]}\end{array}$ & $\begin{array}{c}\text { Inter } \\
{[\mathbf{G W}]}\end{array}$ & $\begin{array}{c}\text { Iso } \\
{[\mathbf{G W}]}\end{array}$ & $\begin{array}{c}\text { Inter } \\
{[\mathbf{G W}]}\end{array}$ & $\begin{array}{c}\text { Iso } \\
{[\mathbf{G W}]}\end{array}$ & $\begin{array}{c}\text { Inter } \\
{[\mathbf{G W}]}\end{array}$ & $\begin{array}{c}\text { Iso } \\
{[\mathbf{G W}]}\end{array}$ & $\begin{array}{c}\text { Inter } \\
{[\mathbf{G W}]}\end{array}$ \\
\hline Nuclear & 0 & 0 & 0 & 0 & 0 & 0 & 0 & 0 \\
\hline Coal & 0 & 0 & 0 & 0 & 0 & 0 & 0 & 0 \\
\hline CCGT & 12.4 & 11.8 & 51.1 & 50.2 & 52.0 & 51.7 & 32.7 & 30.8 \\
\hline OCGT & 8.3 & 9.0 & 52.8 & 53.7 & 34.1 & 34.5 & 21.7 & 23.6 \\
\hline Onshore wind & 19.7 & 19.6 & 59.4 & 59.1 & 104.2 & 111.5 & 41.0 & 41.0 \\
\hline Solar PV & 0 & 0 & 0 & 0.5 & 15.7 & 0 & 0 & 0 \\
\hline
\end{tabular}

Table 8: The capacity mixes in the neighboring countries obtained by (i) ignoring cross-border trade opportunities (Iso) and (ii) explicitly modeling cross-border trade flows (Inter) for the Greenfield 2020 scenario. 


\begin{tabular}{|c|c|c|c|c|c|c|c|c|}
\hline \multirow{2}{*}{ Brownfield 2020 } & \multicolumn{2}{|c|}{ NL } & \multicolumn{2}{c|}{ FR } & \multicolumn{2}{c|}{ DE } & \multicolumn{2}{c|}{ UK } \\
\cline { 2 - 9 } & $\begin{array}{c}\text { Iso } \\
{[\mathbf{G W}]}\end{array}$ & $\begin{array}{c}\text { Inter } \\
{[\mathbf{G W}]}\end{array}$ & $\begin{array}{c}\text { Iso } \\
{[\mathbf{G W}]}\end{array}$ & $\begin{array}{c}\text { Inter } \\
{[\mathbf{G W}]}\end{array}$ & $\begin{array}{c}\text { Iso } \\
{[\mathbf{G W}]}\end{array}$ & $\begin{array}{c}\text { Inter } \\
{[\mathbf{G W}]}\end{array}$ & $\begin{array}{c}\text { Iso } \\
{[\mathbf{G W}]}\end{array}$ & $\begin{array}{c}\text { Inter } \\
{[\mathbf{G W}]}\end{array}$ \\
\hline Nuclear & 0 & 0 & 50.5 & 50.5 & 0 & 0 & 0 & 0 \\
\hline Coal & 0 & 0 & 0 & 0 & 37.2 & 37.2 & 0 & 0 \\
\hline CCGT & 12.5 & 12.5 & 0.6 & 0 & 14.7 & 13.9 & 32.7 & 30.7 \\
\hline OCGT & 8.3 & 8.3 & 52.8 & 53.4 & 34.3 & 35.1 & 21.7 & 23.8 \\
\hline Onshore wind & 19.7 & 19.6 & 59.4 & 53.7 & 103.5 & 111.5 & 41.0 & 41.0 \\
\hline Solar PV & 0 & 0 & 0 & 9.6 & 16.5 & 0 & 0 & 0 \\
\hline
\end{tabular}

Table 9: The capacity mixes in the neighboring countries obtained by (i) ignoring cross-border trade opportunities (Iso) and (ii) explicitly modeling cross-border trade flows (Inter) for the Brownfield 2020 scenario.

\begin{tabular}{|c|c|c|c|c|c|c|c|c|}
\hline \multirow{2}{*}{ Greenfield HRES } & \multicolumn{2}{|c|}{ NL } & \multicolumn{2}{c|}{ FR } & \multicolumn{2}{c|}{ DE } & \multicolumn{2}{c|}{ UK } \\
\cline { 2 - 9 } & $\begin{array}{c}\text { Iso } \\
{[\mathbf{G W}]}\end{array}$ & $\begin{array}{c}\text { Inter } \\
{[\mathbf{G W}]}\end{array}$ & $\begin{array}{c}\text { Iso } \\
{[\mathbf{G W}]}\end{array}$ & $\begin{array}{c}\text { Inter } \\
{[\mathbf{G W}]}\end{array}$ & $\begin{array}{c}\text { Iso } \\
{[\mathbf{G W}]}\end{array}$ & $\begin{array}{c}\text { Inter } \\
{[\mathbf{G W}]}\end{array}$ & $\begin{array}{c}\text { Iso } \\
{[\mathbf{G W}]}\end{array}$ & $\begin{array}{c}\text { Inter } \\
{[\mathbf{G W}]}\end{array}$ \\
\hline Nuclear & 0 & 0 & 0 & 0 & 0 & 0 & 0 & 0 \\
\hline Coal & 0 & 0 & 0 & 0 & 0 & 0 & 0 & 0 \\
\hline CCGT & 8.3 & 6.0 & 39.8 & 38.9 & 31.5 & 32.3 & 25.8 & 24.4 \\
\hline OCGT & 12.4 & 14.8 & 64.1 & 65.1 & 54.7 & 53.8 & 28.6 & 30.0 \\
\hline Onshore wind & 43.9 & 42.2 & 92.1 & 93.6 & 232.1 & 197.3 & 90.4 & 86.9 \\
\hline Solar PV & 25.1 & 24.3 & 52.1 & 50.8 & 121.1 & 117.9 & 0 & 0 \\
\hline
\end{tabular}

Table 10: The capacity mixes in the neighboring countries obtained by (i) ignoring cross-border trade opportunities (Iso) and (ii) explicitly modeling cross-border trade flows (Inter) for the Greenfield HRES scenario.

Besides the impact on the renewable technologies, Figure 8 furthermore shows that ignoring cross-border trade overestimates domestic CCGT (baseload) investments. The explanation for this can be found in Figure 9 , which shows the generation volumes that make up the annual Belgian electricity demand. From this figure it can be seen that a certain share of domestic CCGT generation is being replaced by electricity imports. Given these reduced number of operating hours, it becomes less interesting to invest in a high amount of CCGT installed capacity. Furthermore, the import opportunities increase when power systems have different structures, as shown in the brownfield 2020 scenario. Especially the presence of nuclear in France is a major contributor to this. 


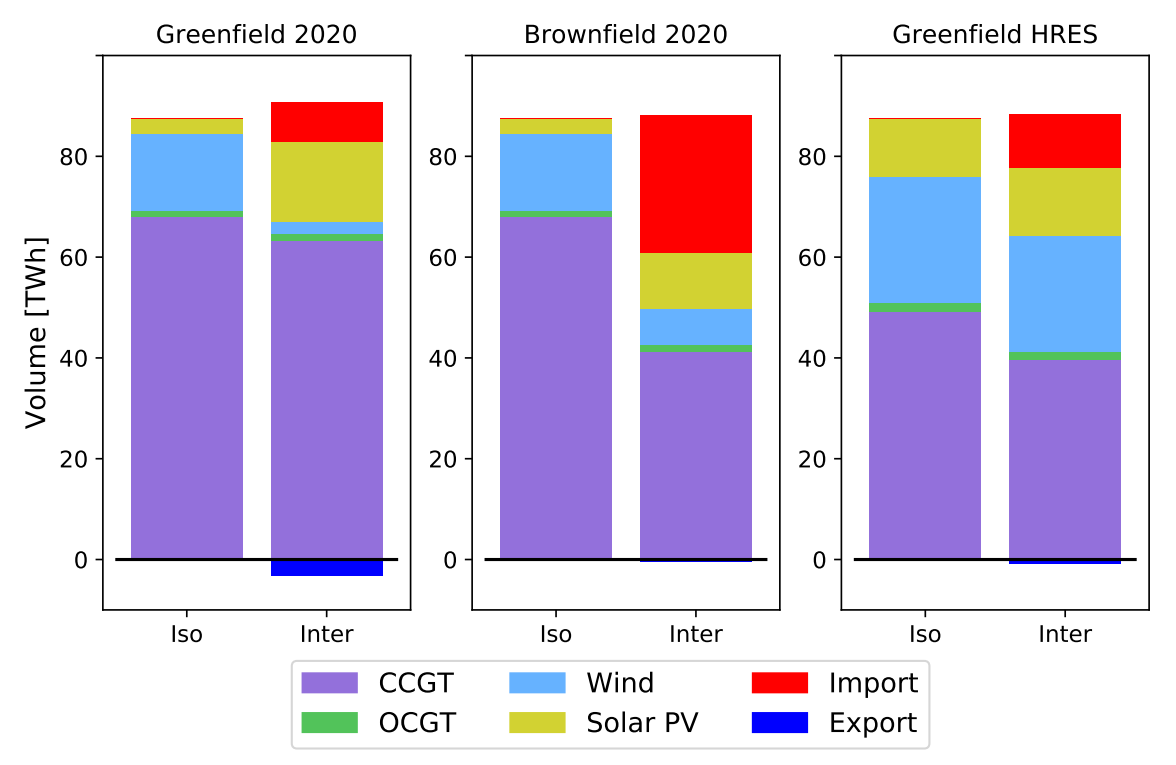

Figure 9: The domestic generation volumes obtained by (i) ignoring cross-border trade opportunities (Iso) and (ii) explicitly modeling cross-border trade flows (Inter) for the three different scenarios.

Turning now to the global generation shares shown in Figure 10, it can be seen that in both greenfield scenarios the overall share of CCGT generation does not change substantially. This indicates that the reduction of CCGT generation in Belgium does not apply for the total system and that the Belgian imports are mostly consisting of CCGT generated electricity. Furthermore, given the fact that total CCGT investments in all countries decrease (see Tables 8 and 10), it can be stated that the presence of interconnectors allows for more efficient baseload investment decisions as less capacity is needed for the same amount of electricity generated. Additionally, Figure 10 shows that in the Brownfield 2020 scenario French nuclear power plants and German coal power plants take up a larger share in the generation mix. Again, this is due to the presence of the interconnections that allow deploying the existing capacities more efficiently. All in all, it can be concluded that interconnections exploit existing capacities more efficiently and lead to more efficient investment decisions. 


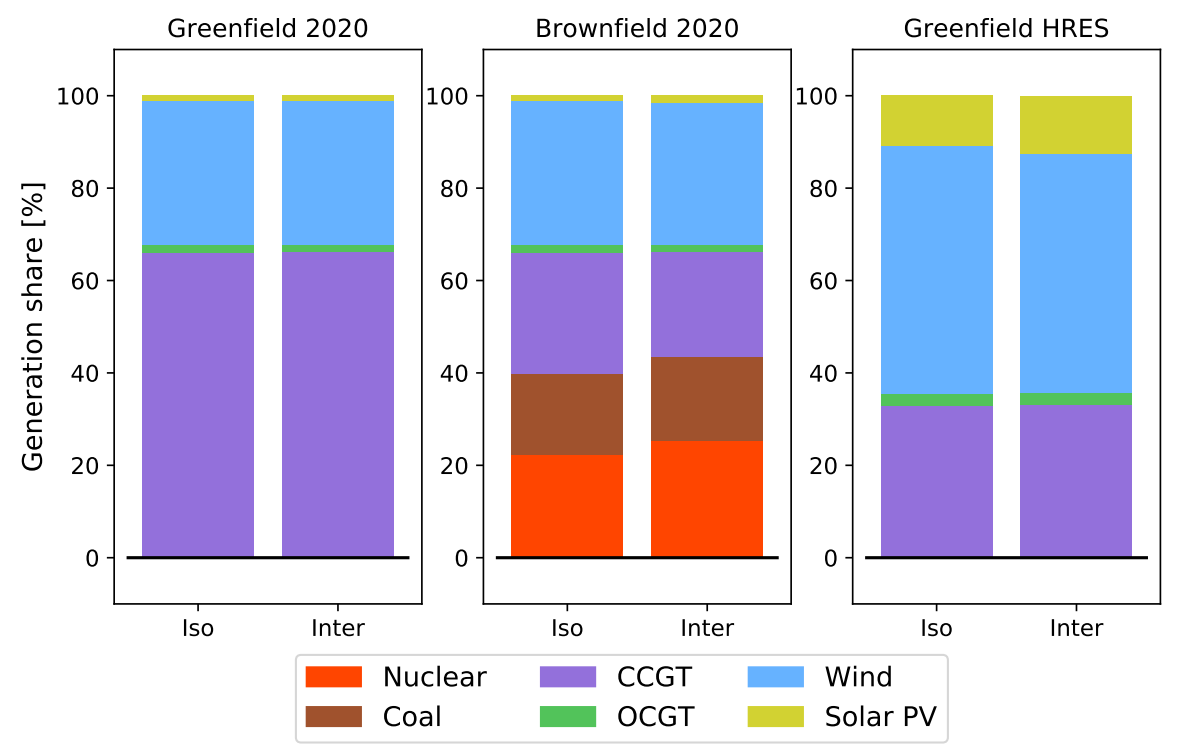

Figure 10: The system-wide generation volumes obtained by (i) ignoring cross-border trade opportunities (Iso) and (ii) explicitly modeling cross-border trade flows (Inter) for the three different scenarios.

\subsubsection{Impact on domestic welfare}

Figure 11 shows the relative domestic welfare gains with respect to domestic costs of the isolated case for all countries in the different scenarios. As can be seen, the welfare gains obtained in the Greenfield 2020 scenario tend to be rather limited (between $0.36 \%$ and $1.51 \%$ ), but increase as the surrounding capacity mixes become more diverse in the Brownfield 2020 scenario. Furthermore, the welfare gains due to cross-border trade become significantly higher for the Greenfield HRES scenario (between $4 \%$ and 14\%).

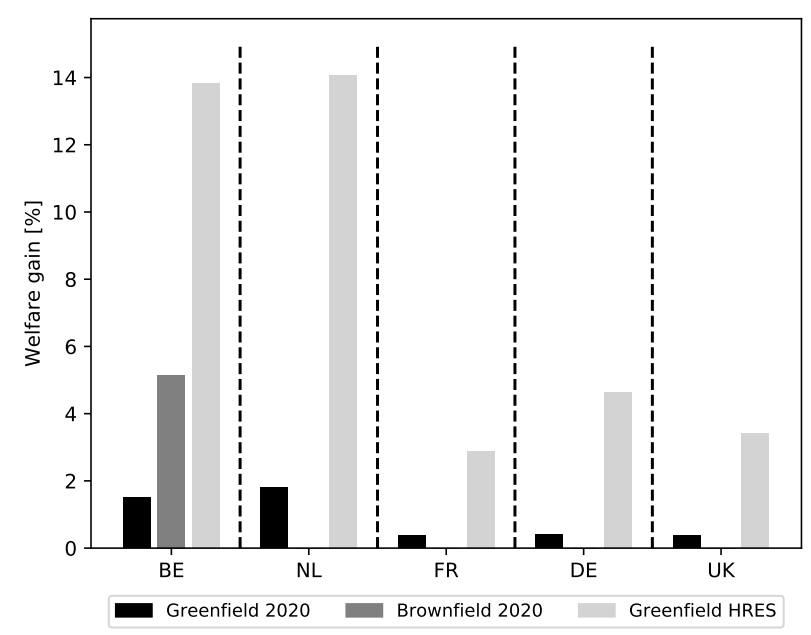

Figure 11: Relative welfare gains with respect to the domestic costs of the isolated case for each country in every scenario.

As explained in Section 3.1.2, the welfare gains shown in Figure 11 are a combination of (i) changes in production costs (CAPEX and OPEX), (ii) changes in trade costs/revenues and (iii) changes in congestion rents. Figure 12 shows the contribution of changes in the different welfare components to the Belgian welfare gains. From this figure three effects stand out. First, ignoring cross-border trade overestimates CAPEX in 
all investigated scenarios as a result of the decrease in CCGT investments.

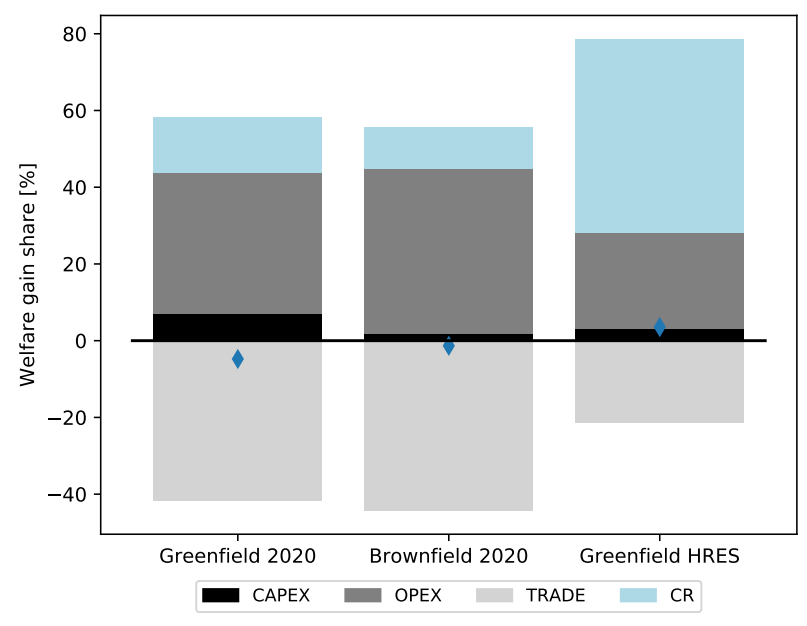

Figure 12: The shares of the welfare components that make up the total Belgian welfare gains.

Second, domestic operational costs decrease as a result of the decrease in domestic electricity generation. However, we see that this decrease goes together with an increase of the trade costs. This is not very surprising since a decrease in domestic generation implies that electricity needs to be imported from elsewhere. We know from the domestic generation shares from Section 4.1.1 that the imported electricity mainly replaces electricity produced by CCGT units. Hence, the net effect of replacing domestic CCGT generation by electricity imports (indicated by the diamond marker in Figure 12) depends on the difference between the marginal cost of CCGT generation and the average price at which the electricity is imported. The marginal cost of electricity generated by CCGT unit is around $51 \mathrm{EUR} / \mathrm{MWh}$ and Table 11 shows the average import price in all scenarios. As can be seen, in the Greenfield 2020 scenario the average import price is higher than the marginal cost of CCGT generation and as a result the OPEX reductions are slightly smaller than the additional import costs. Hence, the net effect on the Belgian welfare is negative. Furthermore, the presence of cheap French nuclear generation in the Brownfield 2020 scenario has a downward effect on the average import price. However, this decrease is not sufficient to offset the cost of domestic CCGT generation. Only in the Greenfield HRES scenario the average import price sinks below the CCGT's marginal cost, which results in the additional import costs being smaller than the OPEX reductions.

Greenfield 2020 Brownfield 2020 Greenfield HRES

\begin{tabular}{cccc}
\hline $\begin{array}{c}\text { Average import price } \\
\text { [EUR/MWh] }\end{array}$ & 57.7 & 52.7 & 43.5 \\
\hline
\end{tabular}

Table 11: Average import costs in the three different scenarios. Only in the Greenfield HRES case the cost of import decreases below the marginal cost of CCGT, leading to reductions in operational costs.

Given this net effect of the OPEX reductions and the trade cost increase, the third aspect that stands out from Figure 12 is that congestion in the system accounts for the major share in domestic welfare gains for the investigated 2020 NTC values. Furthermore, we see that the total congestion rents increase substantially in the greenfield HRES scenarios, indicating that the importance of this welfare component increases as power systems exhibit large amounts of RES. As such, the congestion rent is an importat welfare component that should not be neglected in long-term planning exercises. 


\subsubsection{Sensitivity on available transmission capacity}

To illustrate the impact of the available transmission capacity on the effects observed in Sections 4.1.1 and 4.1 .2 , a sensitivity analysis was performed.

In our analyses, binding RES-targets were imposed for each country. There is evidence that the benefit of exploiting the geographical variations in RES generation profiles increases as the available transmission capacity increases. The evidence comes from the dual variables of the constraints imposing the renewable target for the different countries, which can be interpreted as the necessary support (i.e., subsidy) to achieve the targeted RES share in that respective country. Figure 13 below shows this required RES subsidy for each country in all three scenarios and for varying degrees of interconnection capacity. As can be seen, the required subsidy mostly decreases as the available level of interconnection increases. This means that increased electricity trading facilitates RES expansion since the same RES targets can be reached at a lower cost. For systems with high renewable shares, this effect is most visible.

Furthermore, Figure 14a shows the total welfare gains for the entire system for varying levels of the interconnection capacity. From this figure we see that total welfare gains increase non-linearly with the available transmission capacity, which is in line with the results presented in [26] and [27]. However, the same nonlinear increase is not observed for the Belgian welfare gains shown in Figure 14b. Interestingly, domestic welfare gains reach a maximum for a specific value of the available transmission capacity. Meaning that transmission capacity increases not necessarily lead to additional welfare gains. To explain this, observe Figures 15a and 15b which respectively show the joint contribution of the CAPEX, OPEX \& Trade welfare components and the congestion rent component to the Belgian welfare gains. From these figures it can be seen that joint CAPEX, OPEX \& Trade changes increase the welfare gains in a similar non-linear way as the total system cost reduction (except for the Brownfield 2020 scenario). The congestion rent, however, first increases up to some value of the available transmission capacity and starts to decrease once that value is passed. This evolution can be explained by the two factors that make up the congestion rent, namely the flow over the transmission line and the price spread between the countries/regions connected by that transmission line. Both factors are inversely affected by a transmission capacity increase. While cross-border flows increase when transmission capacity is added, the price spread between the countries decreases. A such, for low NTC values the former effect is dominant leading to a net increase in congestion rent. For high NTC values the latter effect is dominant forcing the congestion rent to decrease.

Note that in this situation, Belgium would not agree to expand the available transmission capacity beyond NTCx2, since this would lead to a decrease in domestic welfare, although the total welfare does increase (see Figure 14a. In these analyses it was assumed that the congestion rents on a specific transmission line were divided equally among the countries interconnected by that transmission line, as indicated by Equations (1) and (2). In order for Belgium to agree to transmission capacity expansion, a larger share of the congestion rent should be allocated to Belgium so that the domestic welfare of Belgium does increase beyond NTCx2.

Finally, from Figure 15 it can be seen that even for substantial increases of the interconnection capacity the congestion rent remains the largest contributor to the domestic welfare gains. This confirms our finding that the congestion rent is an important welfare component to be considered in planning exercises. 


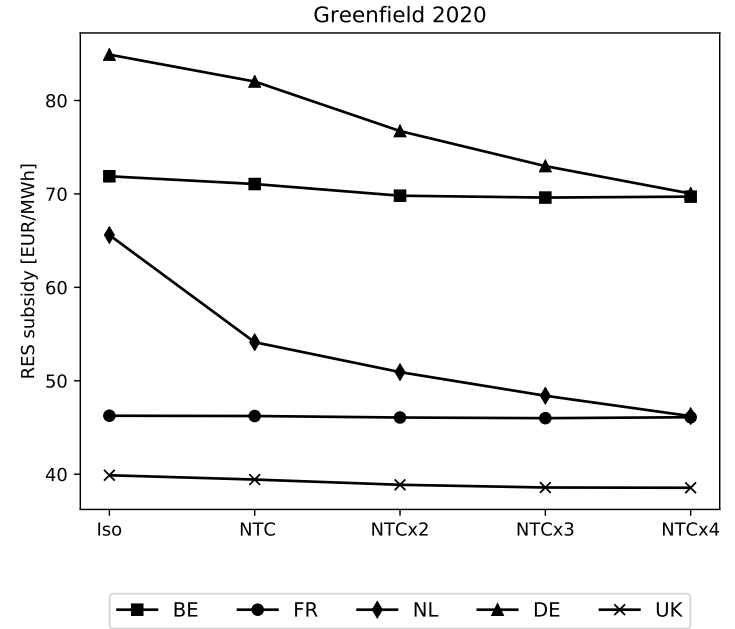

(a)

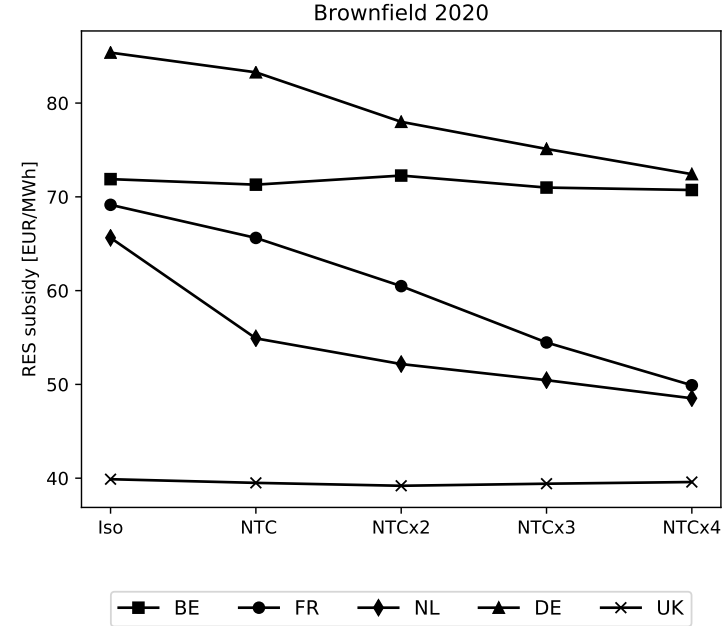

(b)

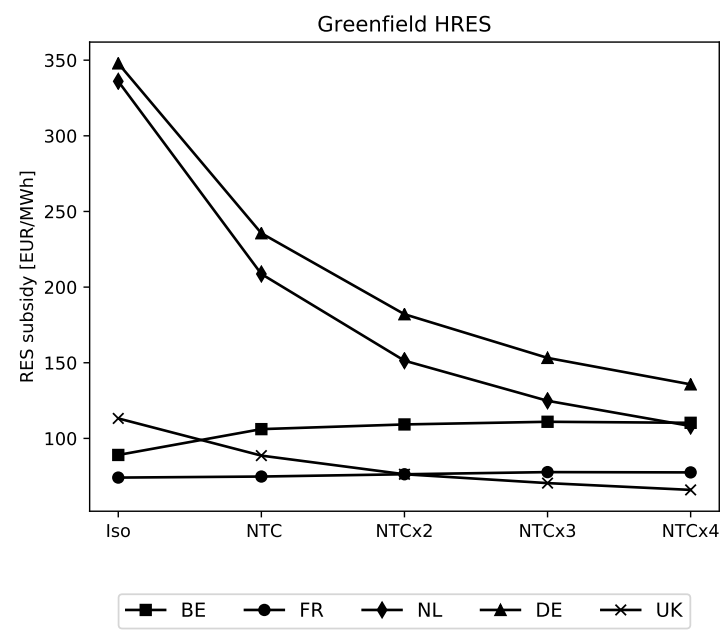

(c)

Figure 13: Evolution of the dual variable related to the RES-share constraint for varying degrees of interconnection capacity for (a) the Greenfield 2020 scenario, (b) the Brownfield 2020 scenario and (c) the Greenfield HRES. 


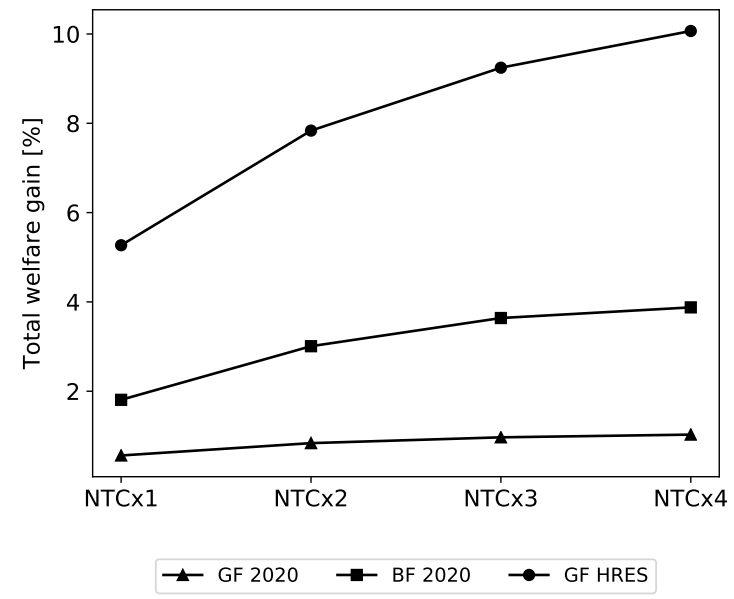

(a)

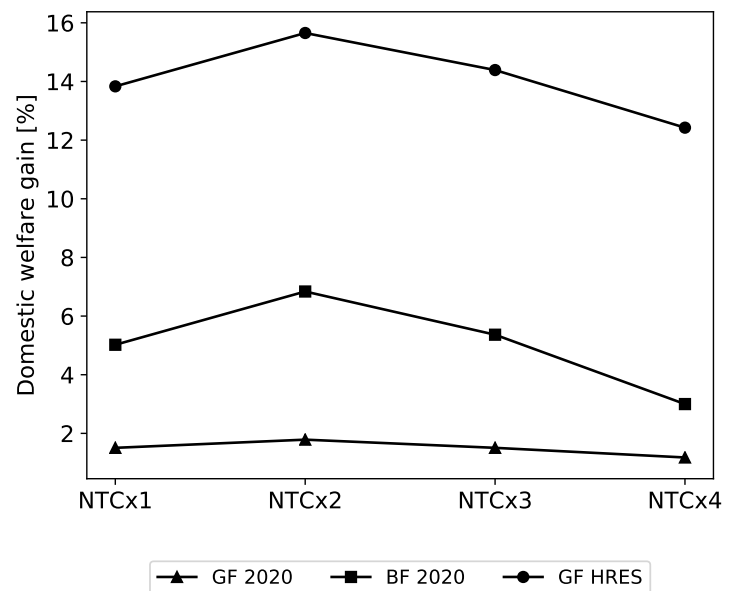

(b)

Figure 14: (a) The total system welfare gains for different NTC values relative to the isolated case. As transmission capacity increases, the total welfare gains increase in a non-linear manner. (b) The domestic (Belgian) welfare gains for different NTC values relative to the isolated case. The domestic welfare gains reach a maximum for a specific value of the available transmission capacity.

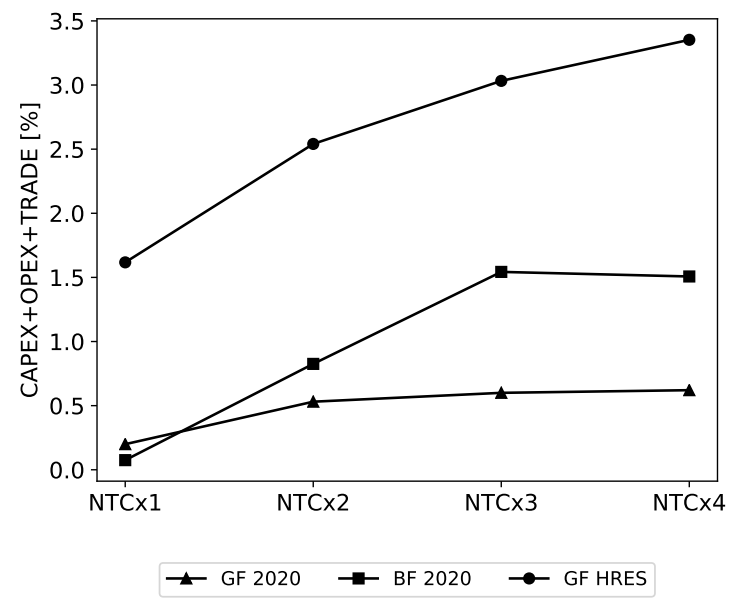

(a)

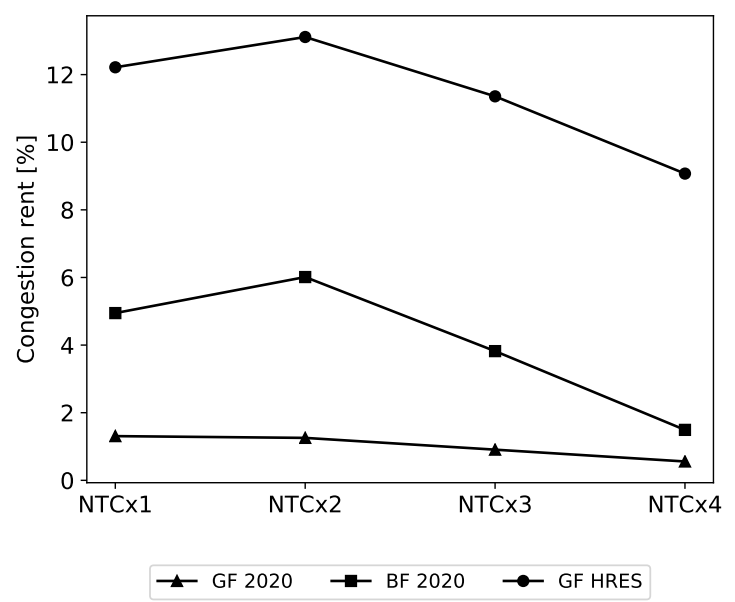

(b)

Figure 15: The contribution of (a) the joint changes in the CAPEX, OPEX \& Trade welfare components and (b) the congestion rents to the domestic welfare gains shown in Figure 14b.the joint changes in the CAPEX, OPEX \& Trade welfare components increase non-linearly with increasing transmission capacity (except in the Brownfield 2020 scenario). The congestion rents increase for low NTC values due to increased transmission flows, but decrease for higher NTC values due to a decreasing price spread between countries. 


\subsection{Performance of methodologies to represent cross-border trade}

In order to evaluate the performance of the three proposed methods, a benchmark needs to be defined against which we can measure the performance of the methods. Recall that the first step is always to make projections of the future electricity demand and the capacity mix in the neighboring countries/regions. The quality of the projections made here is obviously of high importance for the quality of the solution of the optimization model. However, as discussed earlier, these projections can be made following different methodologies, where one is not necessarily better or worse than the other. Therefore, in this work, we compare the accuracy and computational performance of the proposed methods given certain projections made regarding the capacity mix and electricity demand in neighboring countries/zones. In the presented results below, we choose to use the capacity mix that results from the model that co-optimizes investments in all countries (the 'interconnected' model). For this set of assumed capacities, the results of the 'interconnected' model provides a benchmark solution. The performance of the three methodologies are investigated in terms of technology choices, cost estimates and the computational time required to solve the optimization.

\subsubsection{Technology choices}

Figures 16 and 17 show the installed capacities and generated volumes for each technology in Belgium. From these figures it can be seen that endogenizing foreign dispatch decisions, produces the same results as the interconnected co-optimization. Although this might seem a trivial result, it implies that the representation of cross-border trade is accurate given that the assumptions about the neighboring countries are accurate. Hence, instead of bothering with extending the geographical scope and co-optimizing the entire system, one can extend the geographical scope and force the capacity mixes in the neighboring countries to be in line with some pre-defined assumptions (read: scenarios) and obtain perfectly accurate results for the focus area given those assumptions. The crucial part is of course to make accurate assumptions about the surrounding power systems. However, it has to be stated that this is inherent to all long-term planning exercises focusing on one particular country or region. Technically, one could use co-optimization as a strategy for domestic planning. However, given that we cannot control what happens in the neighboring countries, and that reality might differ from the results of an optimization model, co-optimizing is nothing more than a very specific (and perhaps unlikely) scenario.

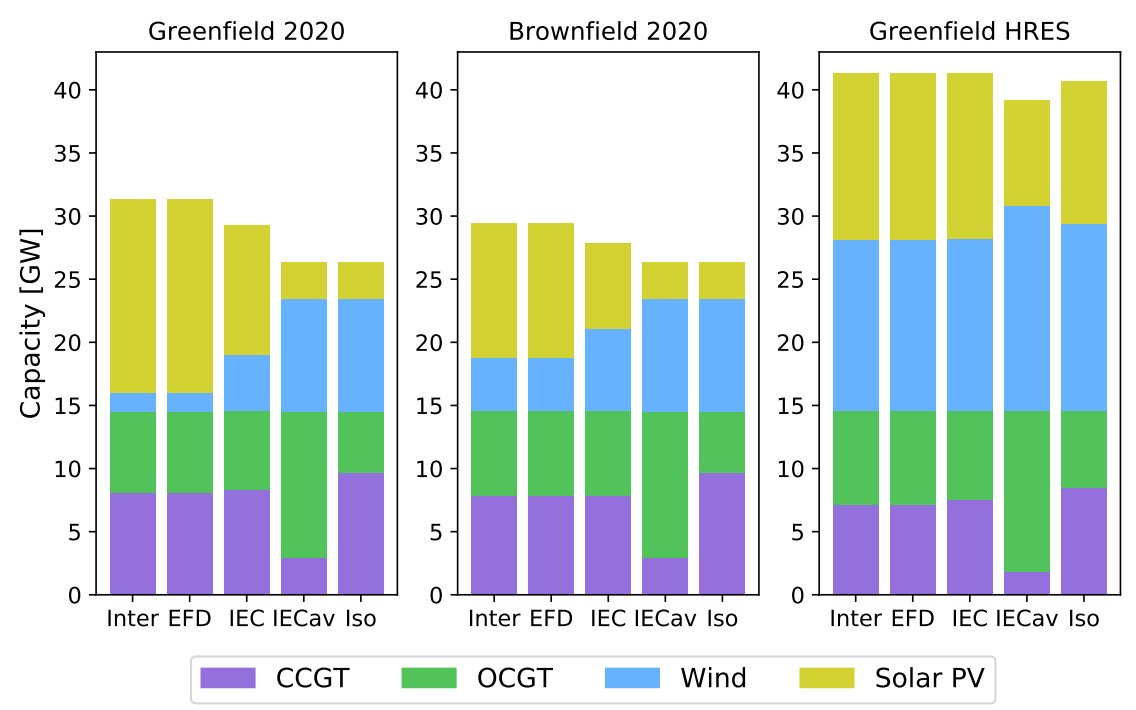

Figure 16: The domestic technology choices obtained by the different methods (Inter: Interconnected; EFD: Endogenous Foreign Dispatch; IEC: Import Export Curves (time-dependent); IECav: Import Export Curves (annual average); Iso: Isolated) for the three different scenarios. 


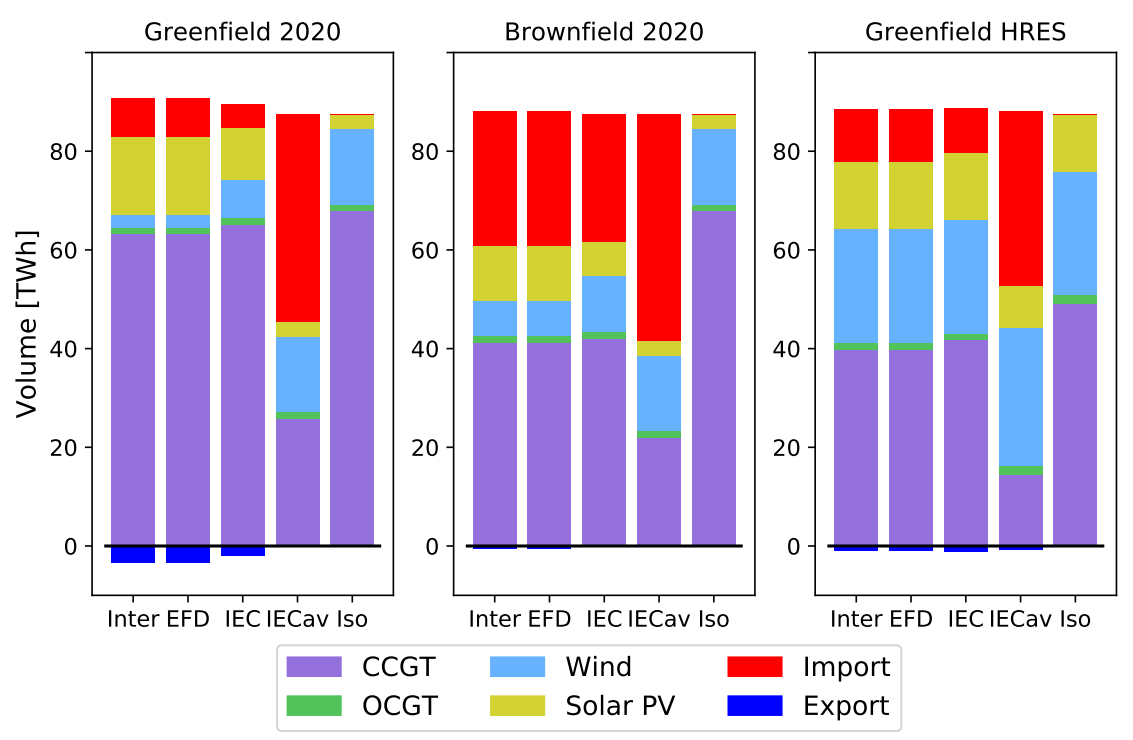

Figure 17: The domestic generation volumes obtained by the different methods (Inter: Interconnected; EFD: Endogenous Foreign Dispatch; IEC: Import Export Curves (time-dependent); IECav: Import Export Curves (annual average); Iso: Isolated) for the three different scenarios.

Concerning the results obtained by using time-dependent import and export curves, it can be seen that also this methodology triggers better investment decisions than ignoring cross-border trade in our analysis. Especially the contribution of CCGT capacity is captured more accurately. However, when it comes to the relative share of wind and solar PV in the capacity mix, still some differences are observed. Furthermore, from Figure 17 it can be seen that in this analysis annual import volumes are underestimated by the method based on import/export curves.

To elaborate on this effect, Figure 18 shows the transmission flows obtained by the method based on import and export curves against the transmission flows obtained by the interconnected model. From Figure 18 a clear correlation between both transmission flows can be seen. Quadrants two and four are substantially less populated than quadrants one and three, indicating that the directions of the transmission flows are mostly maintained when import/export curves are used. Furthermore, a line through the origin emerges that shows the occurence of identical transmission flows. Hence, this line represents the situations in which the import and export curves replicate the transmission flows obtained by the interconnected model. At the same time, all points deviating from this line represent events for which the absence of direct transmission lines between neighboring countries prevent a full equivalence between both methods. As such, we can identify four situations:

A. The events for which the import is underestimated by the import/export curves, appearing in the area enclosed by the positive $\mathrm{x}$-axis and the line through the origin.

B. The events for which the import is overestimated by the import/export curves, appearing in the area enclosed by the positive $\mathrm{y}$-axis and the line through the origin.

C. The events for which the export is underestimated by the import/export curves, appearing in the area enclosed by the negative $\mathrm{x}$-axis and the line through the origin.

D. The events for which the export is overestimated by the import/export curves, appearing in the area enclosed by the negative y-axis and the line through the origin.

The combined effect of these four situations result in the underestimation of net import and export flows. However, since Figure 18 shows the transmission flows on each individual transmission line separately, nothing can be inferred about the net import or export flows. What does stand out is that many data points are 
concentrated on one of the axes. Data points coinciding with the x-axis represent situations for which the import/export curves do not replicate transmission flows that would normally emerge in the interconnected case. These result due to the fact that by using import/export curves the neighboring countries/regions are unable to act as transit countries/regions, facilitating electricity flows that merely pass through a neighboring country. Hereby decreasing the indirect transmission capacity interconnecting Belgium with the rest of the system. Figure 19 illustrates this effect for a specific time step of the Greenfield 2020 scenario. This time step is characterized by large amounts of wind power generation in Germany. In the interconnected case, electricity can flow from Germany to Belgium via The Netherlands and France (in addition to the direct flow on the interconnection between Belgium and Germany). However, this is not possible by using import and export curves that are only designed to model direct transmission flows between the focus country/region and each respective neighboring countries/regions. Similarly, data points coinciding with the y-axis result from increased transit flows through Belgium. Since electricity is unable to flow directly from one neigboring country to another, these flows are diverted through Belgium to reach its destination. This increases import flows on one transmission line and increases export flows on another. An example of this situation is depicted in Figure 20.

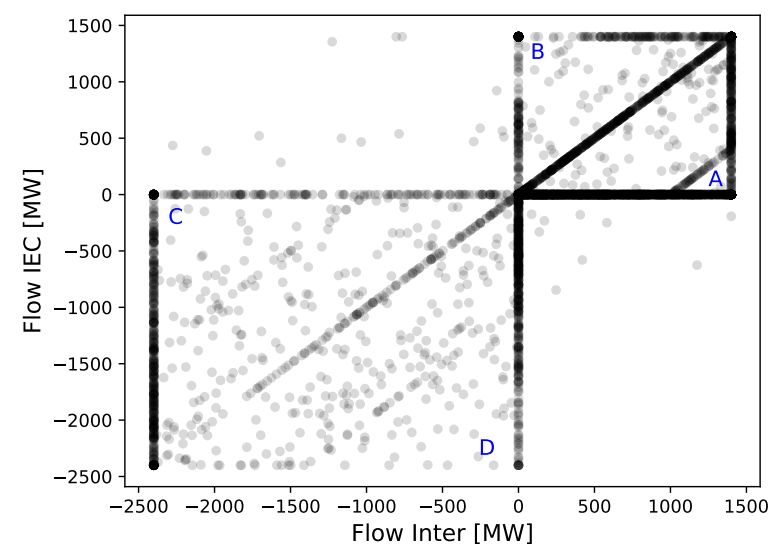

(a) $\mathrm{NL} \rightarrow \mathrm{BE}$

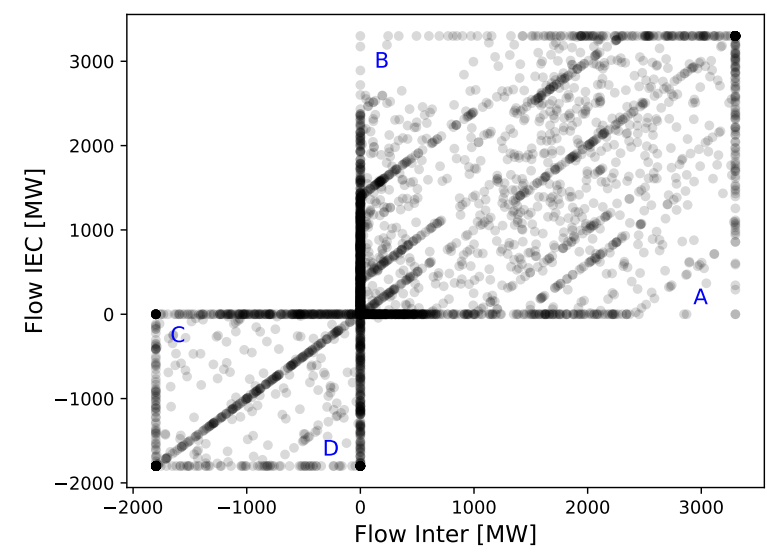

(c) $\mathrm{FR} \rightarrow \mathrm{BE}$

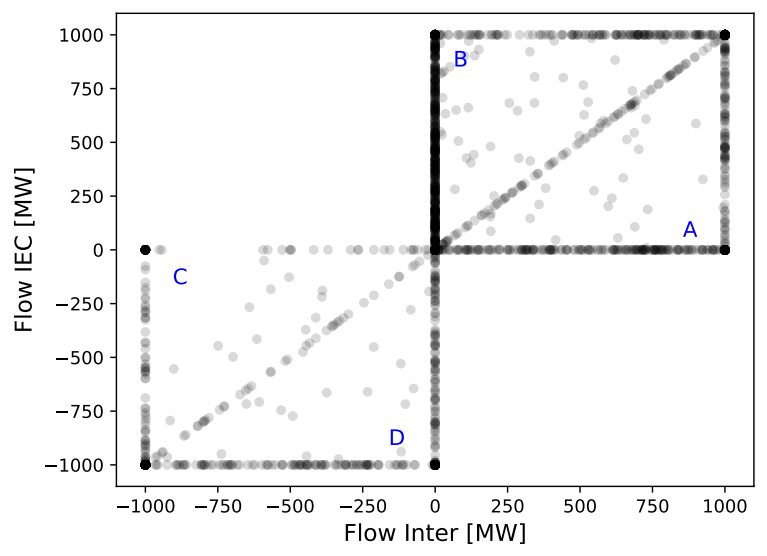

(b) $\mathrm{DE} \rightarrow \mathrm{BE}$

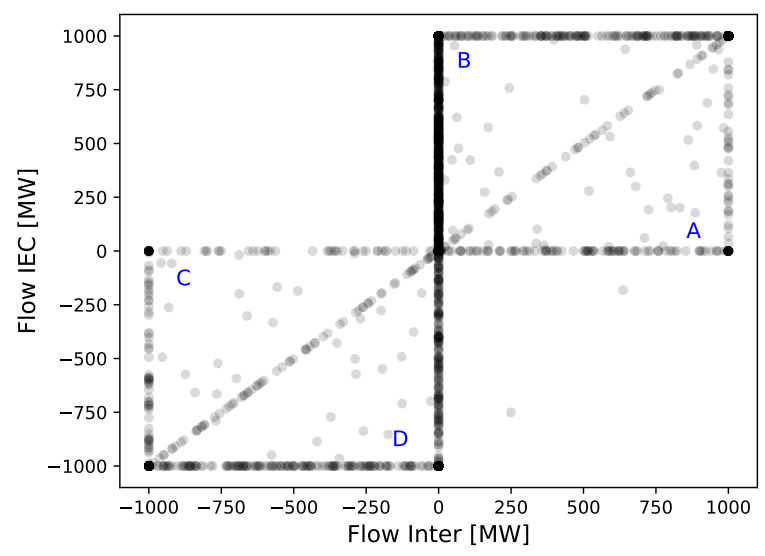

(d) $\mathrm{UK} \rightarrow \mathrm{BE}$

Figure 18: Scatterplot of the transmission flows obtained by (i) the interconnected benchmark model (x-axis) and (ii) the model using import/export curves (y-axis) for the four interconnectors. 


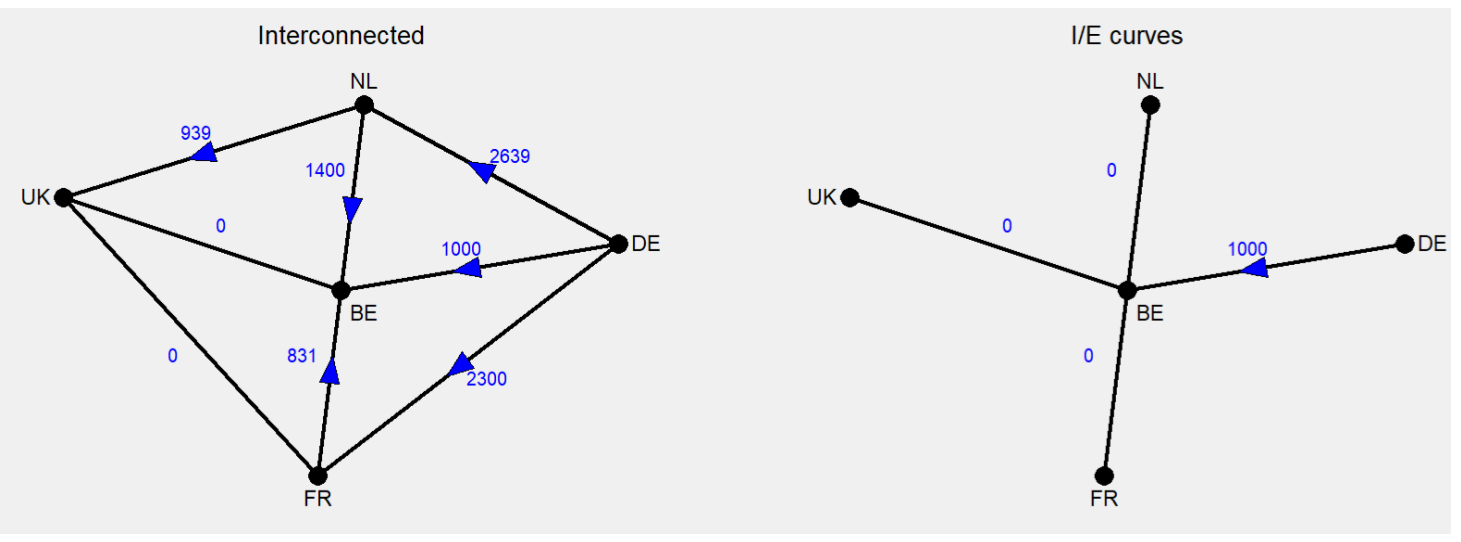

Figure 19: Obtained transmission flows from the interconnected benchmark model (left) and the model using import and export curves (right) for a specific hour. Since import/export curves are unable to model the bi-lateral flows between the neighboring countries, the excess wind generation in Germany cannot reach Belgium through The Netherlands. As such, by using import/export curves neighboring countries cannot act as transit countries for electricity.

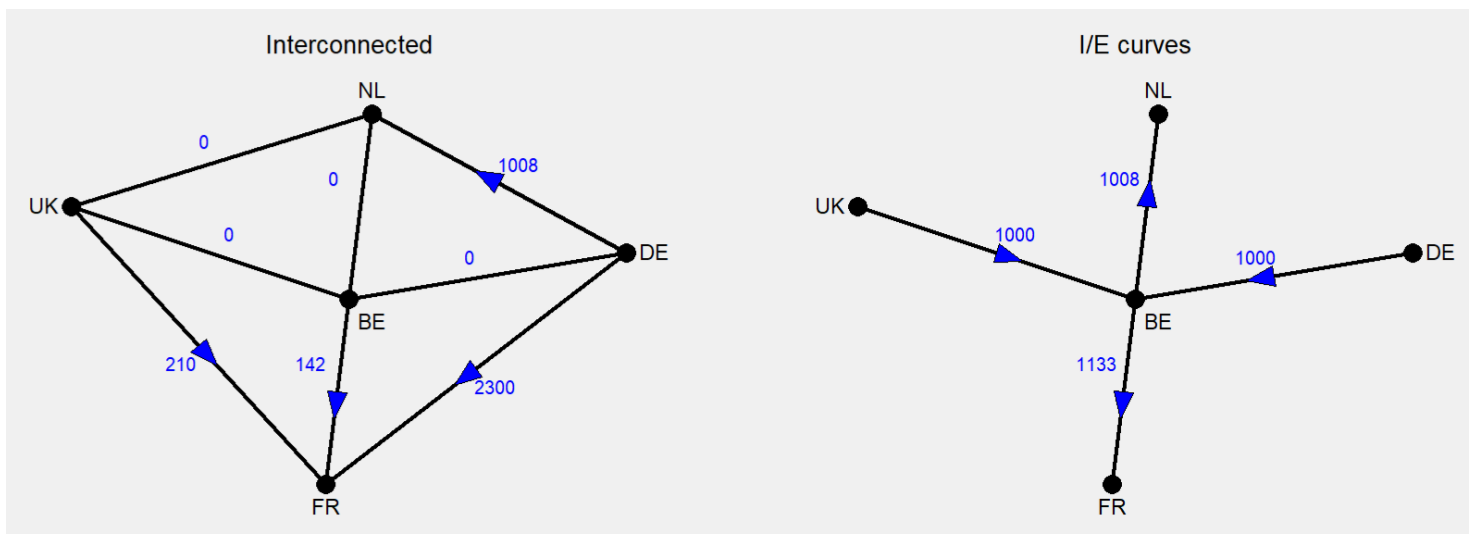

Figure 20: Obtained transmission flows from the interconnected benchmark model (left) and the model using import and export curves (right) for a specific hour. Since import/export curves are unable to model the bilateral flows between the neighboring countries, the excess wind generation in Germany cannot reach France and The Netherlands directly, but has to flow through Belgium instead. As such, by using import/export curves transit flows through Belgium increase.

Finally, Figures 16 and 17 show the impact of using annual average import and export curves. As can be seen, this approach results in roughly the same RES mix as the isolated cases (except for the Greenfield HRES scenario). The reason for this is that since the import and export curve do not vary over time, the different renewable potentials in the neighboring countries fail to affect the resulting capacity mix. Hence, the model is oblivious to any geographic comparative advantages that can be exploited. Furthermore, electricity imports are drastically overestimated due to the fact that (i) the import cost exhibits no correlation with the domestic residual demand, and (ii) the price differences between the neighboring countries are static and often zero ${ }^{4}$, so that less transmission flows are used to facilitate arbitrage among neighboring countries and more import potentials are available to be exploited domestically. In conclusion, these results highlight that a bad representation of cross-border trade potentials is performs worse than ignoring cross-border trade altogether.

\footnotetext{
${ }^{4}$ The average demand divides the average supply curve at the same technology stage for each neighboring country.
} 


\subsubsection{Domestic welfare}

Figure 21 presents the estimation error of the total domestic welfare for the three methods under investigation and the error obtained by ignoring cross-border trade. From this figure it can be seen that endogenizing foreign dispatch decisions results in the same domestic welfare estimate as the interconnected optimization. This comes not as a surprise, since the obtained capacity mix was also identical.

For the time-dependent import/export curves, Figure 21 shows that the domestic welfare is consistently overestimated in all three scenarios. Table 12 shows the relative contribution of each welfare component in this overestimation. As can be seen, using import/export curves underestimates cross-border trade of electricity (decrease in trade costs leads to a positive contribution to welfare) and overestimates domestic OPEX (increased domestic generation leads to a negative contribution to welfare). As such, the gain in welfare due to lower trade costs is more or less compensated by the loss of welfare due to increase OPEX. Considering that the net effect of the OPEX and trade components is small, the welfare overestimation is mainly due to an overestimation of the congestion rent. Looking at the definition of the congestion rent gives two possible causes for this, namely (i) the number of congestion events increases or (ii) the price spread between the countries connected by a congested transmission line increases. Table 13 shows that both effects occur in our analysis. First, the increase in the number congestion events indicates an increased usage of the Belgian transmission lines when interconnections between the neighboring countries are ignored. Second, the increase in average price spread can be explained by the fact that, by ignoring the interconnections between the neighboring countries, less price convergence is achieved with the import/export functions.

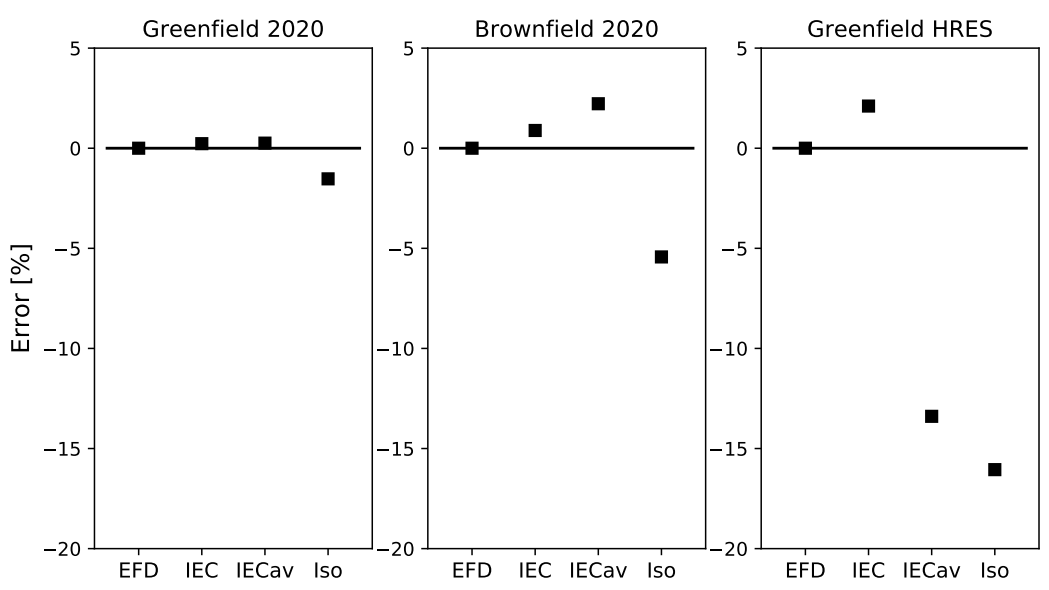

Figure 21: The errors in estimating the domestic welfare for Belgium by using the different methods (EFD: Endogenous Foreign Dispatch; IEC: Import Export Curves (time-dependent); IECav: Import Export Curves (annual average); Iso: Isolated) for the three different scenarios.

\begin{tabular}{ccccc} 
& CAPEX & OPEX & Trade & CR \\
\hline Greenfield 2020 & $-2.28 \%$ & $-43.97 \%$ & $+44.18 \%$ & $\mathbf{+ 9 . 5 5 \%}$ \\
Brownfield 2020 & $+2.98 \%$ & $-32.03 \%$ & $+27.64 \%$ & $\mathbf{+ 3 7 . 3 4 \%}$ \\
Greenfield HRES & $-3.68 \%$ & $-24.93 \%$ & $+21.97 \%$ & $\mathbf{+ 4 9 . 4 0 \%}$ \\
\hline
\end{tabular}

Table 12: The contribution of each welfare component to the overestimation of the domestic welfare obtained by using time-step dependent import/export curves. 


\begin{tabular}{|c|c|c|c|c|}
\hline \multirow{2}{*}{} & \multicolumn{2}{|c|}{$\begin{array}{c}\text { Congested occurences } \\
{[-]}\end{array}$} & \multicolumn{2}{c|}{$\begin{array}{c}\text { Average price spread } \\
\text { (volume weighted) } \\
\text { [EUR/MWh] }\end{array}$} \\
\cline { 2 - 5 } & Inter & IEC & Inter & IEC \\
\hline Greenfield 2020 & 3543 & 4749 & 15.6 & 20.9 \\
\hline Brownfield 2020 & 12997 & 14925 & 11.5 & 13.34 \\
\hline Greenfield HRES & 11239 & 13620 & 67.8 & 69.2 \\
\hline
\end{tabular}

Table 13: The congestion rents are overestimated by the method based on import/export curves due to (i) an increased number of congestion occurences and (ii) an increased price spread between Belgium and the neighboring countries.

The welfare estimates obtained by the annual average import/export curves are better than the welfare estimates of the isolated approach. However, the errors tend to be substantially larger than for the timedependent import/export curves. Moreover, the welfare is overestimated in the Greenfield 2020 and Brownfield 2020 scenarios, but underestimated in the Greenfield HRES scenario. Figure 22 shows the average import/export curve together with the import/export curves of respectively the maximum residual demand (red) and the minimum residual demand (blue) for the French power system in the Greenfield 2020 scenario. As shown, there is a substantial difference between the true time-dependent cross-border representation and the average approximation. As such, it appears that for the low RES scenarios the effect of the high residual demand time steps are underestimated leading to an increase of the domestic welfare estimation. On the contrary, for the HRES scenario the effect of the low residual demand time steps is underestimated leading to an underestimation of the domestic welfare.

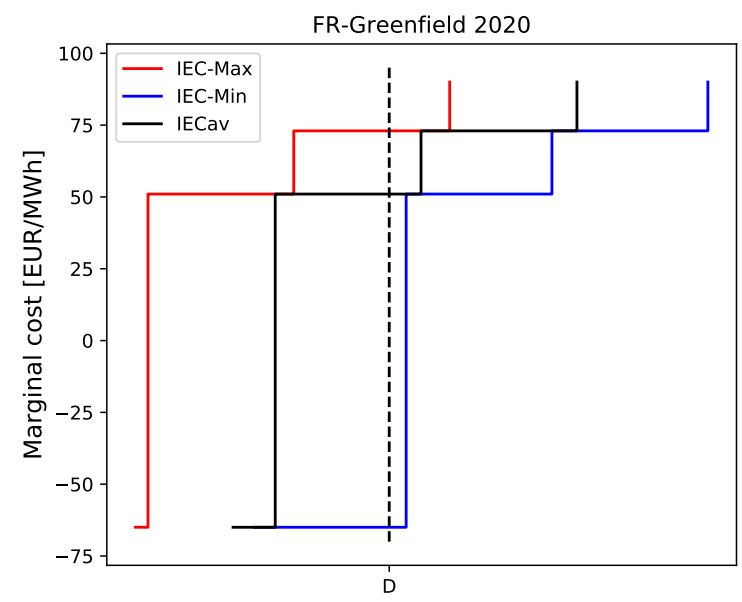

Figure 22: The average annual import/export curve (black); the import/export curve at the maximum residual demand time step (red); and the import/export curve at the minimum residual demand time step (blue) for the French power system in the Greenfield 2020 scenario.

\subsubsection{Sensitivity on available transmission capacity}

It has to be stated that the planning model results are very much case-specific. As such, errors obtained by the methods using cross-border trade curves depend on the considered case. Among aspects that affect the magnitude of these errors are interconnection capacities, structure of the foreign technology mixes and the topology of the transmission network. To illustrate this case-dependency, a sensitivity analysis was performed in which the impact of the available transmission capacity on the welfare-estimation errors was investigated. Table 14 lists the errors obtained by using the three different methods in all scenarios for four different sets of interconnection capacities. This sensitivity analysis, first and foremost confirms the conclusions made 
before. Namely that using time-dependent import/export curves involves inaccurate results with respect to the method that endogenizes foreign dispatch decisions and that annual average import/export curves perform worst and should not be used. Furthermore, for the investigated NTC values, the domestic welfare obtained by the time-dependent import/export curves consistently overestimates the welfare obtained by endogenizing foreign dispatch decisions. However, the magnitude of the error depends strongly on the considered scenario and the level of interconnection.

\begin{tabular}{cccccc} 
Scenario & Method & NTC & NTCx2 & NTCx3 & NTCx4 \\
\hline \multirow{3}{*}{ Greenfield 2020 } & EFD & $+0.0 \%$ & $+0.0 \%$ & $+0.0 \%$ & $+0.0 \%$ \\
& IEC & $+0.23 \%$ & $+0.85 \%$ & $+1.65 \%$ & $+2.30 \%$ \\
& IECav & $+0.25 \%$ & $+3.84 \%$ & $+4.12 \%$ & $+4.44 \%$ \\
\hline \multirow{3}{*}{ Brownfield 2020 } & EFD & $+0.0 \%$ & $+0.0 \%$ & $+0.0 \%$ & $+0.0 \%$ \\
& IEC & $+0.89 \%$ & $+3.81 \%$ & $+8.23 \%$ & $+11.72 \%$ \\
& IECav & $+2.22 \%$ & $+10.16 \%$ & $+17.31 \%$ & $+2.52 \%$ \\
\hline \multirow{3}{*}{ Greenfield HRES } & EFD & $+0.0 \%$ & $+0.0 \%$ & $+0.0 \%$ & $+0.0 \%$ \\
& IEC & $+2.11 \%$ & $+6.37 \%$ & $+12.15 \%$ & $+16.53 \%$ \\
& IECav & $-13.39 \%$ & $-12.38 \%$ & $-10.64 \%$ & $-8.16 \%$ \\
\hline
\end{tabular}

Table 14: The errors in estimating the domestic welfare for Belgium by using the different methods (EFD: Endogenous Foreign Dispatch; IEC: Import Export Curves (time-dependent); IECav: Import Export Curves (annual average); Iso: Isolated) for the three scenarios and four different levels of interconnection.

\subsubsection{Computational time}

Figure 23 shows the computational time it takes to solve a planning model using the different methodologies investigated in this paper. It is apparent from this figure that ignoring cross-border trade of electricity is computationally most efficient (average computation time of 3 seconds). At the other end of the graph we find the fully interconnected co-optimization which takes around 110 seconds to reach the solution. Considering the proposed methodologies, it can be seen that endogenizing dispatch decisions in the neighboring countries for the system at hand takes on average 27 seconds to solve, while using import and export curves (both time-dependent and annual average) can reduce the computational time even further to 9 seconds. Given that the error in technology choices and cost estimated were limited, using time-dependent import and export curves designed according to our proposed method, can be seen as an alternative to fixing the capacities in the neighboring countries when the computational tractability of the planning model might be hampered. Using annual average import/export curves is not recommended.

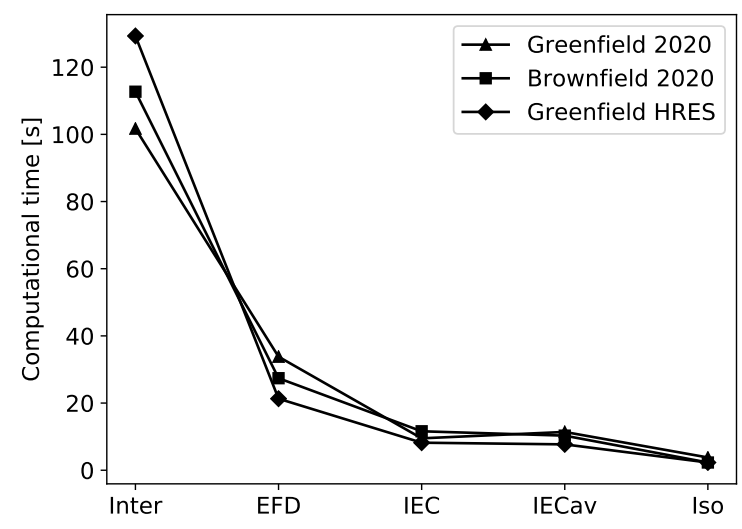

Figure 23: The computational time required to solve a planning model using the different methods (EFD: Endogenous Foreign Dispatch; IEC: Import Export Curves (time-dependent); IECav: Import Export Curves (annual average); Iso: Isolated) for the three different scenarios. 


\section{Conclusion}

Long-term energy-system optimization and power-system models are frequently used to analyse transition pathways of the energy/power system in a certain country or region. As such, these models provide valuable insights for policy makers. Frequently, the geographical scope of these models is confined to a single country/region on which is focused. However, electricity networks are increasingly interconnected and are recognized to be an important provider of flexibility, particularly in highly renewable electrical power systems.

It is important to highlight that planning studies should take care in how import and export flows are accounted for in the domestic welfare projections. In this paper we have derived several welfare components that need to be included in the domestic welfare estimation. These components include (i) the the consumer value, (ii) the production cost (CAPEX and OPEX), (iii) the costs or revenues related to electricity trade and (iv) the congestion rents. To the best of the authors' knowledge, current national planning models do not make this distinction, leading to underestimations of the domestic costs. Therefore, we recommend to always perform an ex-post re-evaluation of the cross-border trade cost.

The first aim of this paper is to assess the impact of neglecting cross-border trade opportunities in long-term energy-system planning models. A first conclusion is that neglecting cross-border trade opportunities affects both domestic welfare projections and domestic technology choices (i.e., the capacity mix deemed optimal by the model). In terms of welfare projections, neglecting cross-border trade leads to an underestimation of the domestic welfare (1.51 \% in Greenfield 2020, 5.0\% in Brownfield 2020 and 13.8\% in Greenfield HRES). For the investigated NTC values, a major share of welfare gains induced by cross-border trade appears as congestion rent revenues. In terms of technology choices, ignoring cross-border trade leads to different investments in conventional and renewable technologies. By accounting for cross-border trade potentials, long-term energy-system optimization models are able to benefit from geographical variations in capacity mixes, differences in potential of renewable energy sources and geographical smoothing of renewable generation and the ability to smooth the variability of electricity demand and renewable generation time series. However, if the modeling of trade flows is ignored, these effects fail to be exploited endogenously by the model. As such, confining the scope of the model to a limited, though highly interconnected geographical area, requires a correct representation of the cross-border trade potential of neighboring regions.

The second aim of this paper was to investigate the performance of three methods to improve the modelling of cross-border trade flows in single-country/region planning models. In order to properly capture cross-border trade opportunities, there is first of all a need for consistent scenarios describing the evolution of the power system in the neighboring countries. These scenarios are necessary since all geographic effects that could be exploited depend on the structure of the foreign power systems. A first method entails expanding the geographical scope and endogenizing the dispatch decisions in all neighboring countries, while fixing the foreign capacities in line with the generated scenarios. This approach results in accurate planning model outcomes for the focus area/country, while reducing the computational cost from 110 to 27 seconds for the simple model used in this study. Therefore, this is the preferable approach. A second approach is based on the usage of import and export curves, i.e., a set of price-quantity pairs that reflect each neighboring country's potential to export and willingness to import. Our analysis revealed that using properly designed import/export curves can reduce computational time, but also introduce a loss of accuracy. The main drawback of this approach is that is neglects bi-lateral power flows between neighboring countries. As a result, the geographical effects are exploited to a lesser extent since the neighboring countries are unable to act as transit countries and hereby reducing the effective transmission capacity. Another difficulty emerges when one wants to include storage technologies or technical requirements (e.g., minimum up- and down times) that require inter-temporal constraints. These inter-temporal aspects can pose a great challenge in the design of adequate import/export curves and might require additional modeling techniques. Since the computational time when using import/export curves is lower than is required by endogenizing the foreign dispatch decisions, this method is seen as a viable alternative when one is interested in modeling cross-border trade flows while facing computational limitations. Finally, due to a lack of transparency in current planning studies, it is not unthinkable that a simplified approach such as our third approach (using annual average cross-border trade curves) is being adopted today. However, our results indicate that this 
approach is flawed and therefore we do not recommend to represent cross-border trade potentials in this way.

\section{Acknowledgement}

The research of Tim Mertens is supported by a PhD grant provided by the Flemish Institute for Technological Research (VITO). 


\section{References}

[1] R. Loulou, U. Remme, A. Kanudia, A. Lehtila, and G. Goldstein, "Documentation for the times model part ii," tech. rep., Energy technology systems analysis programme (ETSAP), 2005.

[2] W. Short, P. Sullivan, T. Mai, M. Mowers, C. Uriarte, N. Blair, D. Heimiller, and A. Martinez, "Regional energy deployment system (reeds)," tech. rep., National Renewable Energy Laboratory (NREL), Golden, CO (United States), 2011.

[3] D. Devogelaer, J. Duerinck, D. Gusbin, Y. Marenne, W. Nijs, M. Orsini, and M. Pairon, "Towards 100\% renewable energy in belgium by 2050," tech. rep., Belgium: FPB, ICEDD, VITO, 2012.

[4] A. Chiodi, M. Gargiulo, F. Rogan, J. Deane, D. Lavigne, U. K. Rout, and B. P. Ó. Gallachóir, "Modelling the impacts of challenging 2050 european climate mitigation targets on ireland's energy system," Energy Policy, vol. 53, pp. 169-189, 2013.

[5] H. Lund and B. V. Mathiesen, "Energy system analysis of $100 \%$ renewable energy systems - the case of denmark in years 2030 and 2050," Energy, vol. 34, no. 5, pp. 524-531, 2009.

[6] N. Strachan, N. Balta-Ozkan, D. Joffe, K. McGeevor, and N. Hughes, "Soft-linking energy systems and gis models to investigate spatial hydrogen infrastructure development in a low-carbon uk energy system," International Journal of Hydrogen Energy, vol. 34, no. 2, pp. 642-657, 2009.

[7] D. Martinsen, J. Linssen, P. Markewitz, and S. Vögele, "Ccs: A future co2 mitigation option for germany? - a bottom-up approach," Energy policy, vol. 35, no. 4, pp. 2110-2120, 2007.

[8] J. Deane, G. Drayton, and B. Ó. Gallachóir, "The impact of sub-hourly modelling in power systems with significant levels of renewable generation," Applied Energy, vol. 113, pp. 152-158, 2014.

[9] A. Pina, C. A. Silva, and P. Ferrão, "High-resolution modeling framework for planning electricity systems with high penetration of renewables," Applied Energy, vol. 112, pp. 215-223, 2013.

[10] G. Haydt, V. Leal, A. Pina, and C. A. Silva, "The relevance of the energy resource dynamics in the mid/long-term energy planning models," Renewable energy, vol. 36, no. 11, pp. 3068-3074, 2011.

[11] P. Nahmmacher, E. Schmid, L. Hirth, and B. Knopf, "Carpe diem: A novel approach to select representative days for long-term power system modeling," Energy, vol. 112, pp. 430-442, 2016.

[12] K. Poncelet, H. Höschle, E. Delarue, A. Virag, and W. D'haeseleer, "Selecting representative days for capturing the implications of integrating intermittent renewables in generation expansion planning problems," IEEE Transactions on Power Systems, vol. 32, no. 3, pp. 1936-1948, 2016.

[13] S. Simoes, M. Zeyringer, D. Mayr, T. Huld, W. Nijs, and J. Schmidt, "Impact of different levels of geographical disaggregation of wind and pv electricity generation in large energy system models: A case study for austria," Renewable energy, vol. 105, pp. 183-198, 2017.

[14] K. Poncelet, E. Delarue, D. Six, J. Duerinck, and W. D'haeseleer, "Impact of the level of temporal and operational detail in energy-system planning models," Applied Energy, vol. 162, pp. 631-643, 2016.

[15] M. Welsch, P. Deane, M. Howells, B. Ó. Gallachóir, F. Rogan, M. Bazilian, and H.-H. Rogner, "Incorporating flexibility requirements into long-term energy system models-a case study on high levels of renewable electricity penetration in ireland," Applied energy, vol. 135, pp. 600-615, 2014.

[16] B. S. Palmintier and M. D. Webster, "Impact of operational flexibility on electricity generation planning with renewable and carbon targets," IEEE Transactions on Sustainable Energy, vol. 7, no. 2, pp. 672684, 2015.

[17] B. S. Palmintier and M. D. Webster, "Heterogeneous unit clustering for efficient operational flexibility modeling," IEEE Transactions on Power Systems, vol. 29, no. 3, pp. 1089-1098, 2013.

[18] J. Deane, A. Chiodi, M. Gargiulo, and B. P. Ó. Gallachóir, "Soft-linking of a power systems model to an energy systems model," Energy, vol. 42, no. 1, pp. 303-312, 2012.

[19] O. Balyk, K. S. Andersen, S. Dockweiler, M. Gargiulo, K. Karlsson, R. Næraa, S. Petrović, J. Tattini, L. B. Termansen, and G. Venturini, "Times-dk: technology-rich multi-sectoral optimisation model of the danish energy system," Energy Strategy Reviews, vol. 23, pp. 13-22, 2019. 
[20] B. Fais, I. Keppo, M. Zeyringer, W. Usher, and H. Daly, "Impact of technology uncertainty on future low-carbon pathways in the uk," Energy Strategy Reviews, vol. 13, pp. 154-168, 2016.

[21] A. K. Riekkola, C. Berg, E. O. Ahlgren, P. Söderholm, et al., "Challenges in soft-linking: the case of emec and times-sweden," National Institute of Economic Research (133), 2013.

[22] F. Amorim, A. Pina, H. Gerbelová, P. P. da Silva, J. Vasconcelos, and V. Martins, "Electricity decarbonisation pathways for 2050 in portugal: A times (the integrated markal-efom system) based approach in closed versus open systems modelling," Energy, vol. 69, pp. 104-112, 2014.

[23] B. P. Ó Gallachóir, A. Chiodi, M. Gargiulo, P. Deane, D. Lavigne, and U. K. Rout, "Irish times energy systems model," 2012.

[24] L. Von Bremen, "Large-scale variability of weather dependent renewable energy sources," in Management of weather and climate risk in the energy industry, pp. 189-206, Springer, 2010.

[25] D. Heide, L. Von Bremen, M. Greiner, C. Hoffmann, M. Speckmann, and S. Bofinger, "Seasonal optimal mix of wind and solar power in a future, highly renewable europe," Renewable Energy, vol. 35, no. 11, pp. 2483-2489, 2010.

[26] D. P. Schlachtberger, T. Brown, S. Schramm, and M. Greiner, "The benefits of cooperation in a highly renewable european electricity network," Energy, vol. 134, pp. 469-481, 2017.

[27] Y. Li, Z. Lukszo, and M. Weijnen, "The impact of inter-regional transmission grid expansion on china's power sector decarbonization," Applied energy, vol. 183, pp. 853-873, 2016.

[28] B. A. Frew and M. Z. Jacobson, "Temporal and spatial tradeoffs in power system modeling with assumptions about storage: An application of the power model," Energy, vol. 117, pp. 198-213, 2016.

[29] N. E. Koltsaklis and A. S. Dagoumas, "State-of-the-art generation expansion planning: A review," Applied energy, vol. 230, pp. 563-589, 2018.

[30] T. Mai, E. Drury, K. Eurek, N. Bodington, A. Lopez, and A. Perry, "Resource planning model: an integrated resource planning and dispatch tool for regional electric systems," tech. rep., National Renewable Energy Lab.(NREL), Golden, CO (United States), 2013.

[31] C. Müller, A. Hoffrichter, L. Wyrwoll, C. Schmitt, M. Trageser, T. Kulms, D. Beulertz, M. Metzger, M. Duckheim, M. Huber, et al., "Modeling framework for planning and operation of multi-modal energy systems in the case of germany," Applied Energy, vol. 250, pp. 1132-1146, 2019.

[32] R. Pattupara and R. Kannan, "Alternative low-carbon electricity pathways in switzerland and it's neighbouring countries under a nuclear phase-out scenario," Applied energy, vol. 172, pp. 152-168, 2016.

[33] M. Fürsch, S. Hagspiel, C. Jägemann, S. Nagl, D. Lindenberger, and E. Tröster, "The role of grid extensions in a cost-efficient transformation of the european electricity system until 2050," Applied Energy, vol. 104, pp. 642-652, 2013.

[34] F. Meinke-Hubeny, L. P. de Oliveira, J. Duerinck, P. Lodewijks, and R. Belmans, "Energy transition in belgium-choices and costs," 2017.

[35] N. E. Koltsaklis, A. S. Dagoumas, G. M. Kopanos, E. N. Pistikopoulos, and M. C. Georgiadis, "A spatial multi-period long-term energy planning model: a case study of the greek power system," Applied Energy, vol. 115, pp. 456-482, 2014.

[36] N. E. Koltsaklis and M. C. Georgiadis, "A multi-period, multi-regional generation expansion planning model incorporating unit commitment constraints," Applied Energy, vol. 158, pp. 310-331, 2015.

[37] V. Krakowski, E. Assoumou, V. Mazauric, and N. Maïzi, "Reprint of feasible path toward 40-100\% renewable energy shares for power supply in france by 2050: A prospective analysis," Applied energy, vol. 184, pp. 1529-1550, 2016.

[38] R. Kannan, "Uncertainties in key low carbon power generation technologies-implication for uk decarbonisation targets," Applied Energy, vol. 86, no. 10, pp. 1873-1886, 2009.

[39] "Ten year network development plan," tech. rep., Entso-e, 2018.

[40] "Projected costs of generating electricity, 2015 edition," tech. rep., International Energy Agency (IEA), Nuclear Energy Agency (NEA), Paris, France, 2015. 